Supporting Information

\title{
Practical synthesis of azobenzenophanes
}

\author{
Hong-Min Kang, Hee-Yeon Kim, Jin-Woo Jung and Cheon-Gyu Cho*
}

Department of Chemistry, Hanyang University, Seoul 131-791, Korea

\section{Table of Contents}

General Experimental Methods --------------------------------------------- S2

Copies of ${ }^{1} \mathrm{H} /{ }^{13} \mathrm{C}$ NMR spectra of 12

$\mathrm{S} 3-\mathrm{S} 4$

Copy of ${ }^{1} \mathrm{H} /{ }^{13} \mathrm{C}$ NMR spectra of $\mathbf{1 3}$

$\mathrm{S} 5-\mathrm{S} 6$

Copy of ${ }^{1} \mathrm{H} /{ }^{13} \mathrm{C}$ NMR spectra of 2a

$\mathrm{S} 7-\mathrm{S} 8$

Copy of ${ }^{1} \mathrm{H} /{ }^{13} \mathrm{C}$ NMR spectra of $\mathbf{1 5}$

$\mathrm{S} 9-\mathrm{S} 10$

Copy of ${ }^{1} \mathrm{H} /{ }^{13} \mathrm{C}$ NMR spectra of $\mathbf{1 6}$

$\mathrm{S} 11-\mathrm{S} 12$

Copy of ${ }^{1} \mathrm{H} /{ }^{13} \mathrm{C}$ NMR spectra of $\mathbf{1 7}$

$\mathrm{S} 13-\mathrm{S} 14$

Copy of ${ }^{1} \mathrm{H} /{ }^{13} \mathrm{C}$ NMR spectra of $\mathbf{1 9}$

$\mathrm{S} 15-\mathrm{S} 16$

Copy of ${ }^{1} \mathrm{H} /{ }^{13} \mathrm{C}$ NMR spectra of 20

$\mathrm{S} 17-\mathrm{S} 18$

Copy of ${ }^{1} \mathrm{H} /{ }^{13} \mathrm{C}$ NMR spectra of 22

$\mathrm{S} 19-\mathrm{S} 20$

Copy of ${ }^{1} \mathrm{H} /{ }^{13} \mathrm{C}$ NMR spectra of $\mathbf{2 c}$

$\mathrm{S} 21-\mathrm{S} 22$

Copy of ${ }^{1} \mathrm{H} /{ }^{13} \mathrm{C}$ NMR spectra of 23

$\mathrm{S} 23-\mathrm{S} 24$

Copy of ${ }^{1} \mathrm{H} /{ }^{13} \mathrm{C}$ NMR spectra of $\mathbf{2 4}$

$\mathrm{S} 25$ - S26

Copy of ${ }^{1} \mathrm{H} /{ }^{13} \mathrm{C}$ NMR spectra of 25

$\mathrm{S} 27-\mathrm{S} 28$

Copy of ${ }^{1} \mathrm{H} /{ }^{13} \mathrm{C}$ NMR spectra of $\mathbf{2 6}$

$\mathrm{S} 29-\mathrm{S} 30$

Copy of ${ }^{1} \mathrm{H} /{ }^{13} \mathrm{C}$ NMR spectra of bis(3-iodophenyl)methanol

S31 - S32

Copy of ${ }^{1} \mathrm{H} /{ }^{13} \mathrm{C}$ NMR spectra of $\mathbf{2 8}$

S33 - S34

Copy of ${ }^{1} \mathrm{H} /{ }^{13} \mathrm{C}$ NMR spectra of $\mathbf{2 9}$

S 35 - S36

Copy of ${ }^{1} \mathrm{H} /{ }^{13} \mathrm{C}$ NMR spectra of $\mathbf{3 0}$

S37 - S38 
General Methods. ${ }^{1} \mathrm{H}$ NMR spectra were recorded at $400 \mathrm{MHz}$ and ${ }^{13} \mathrm{C} \mathrm{NMR}$ spectra at $100 \mathrm{MHz}$, with either TMS $(\delta=0)$ or the signal for residual $\mathrm{CHCl}_{3}$ in the $\mathrm{CDCl}_{3}$ solvent $(\delta=7.24)$ as internal standards. $J$ values are reported in Hz. High resolution mass spectra were measured by using FAB method. Flash column chromatography was performed with 230-400 mesh grade silica-gel. All solvents used were purified according to standard procedures. 


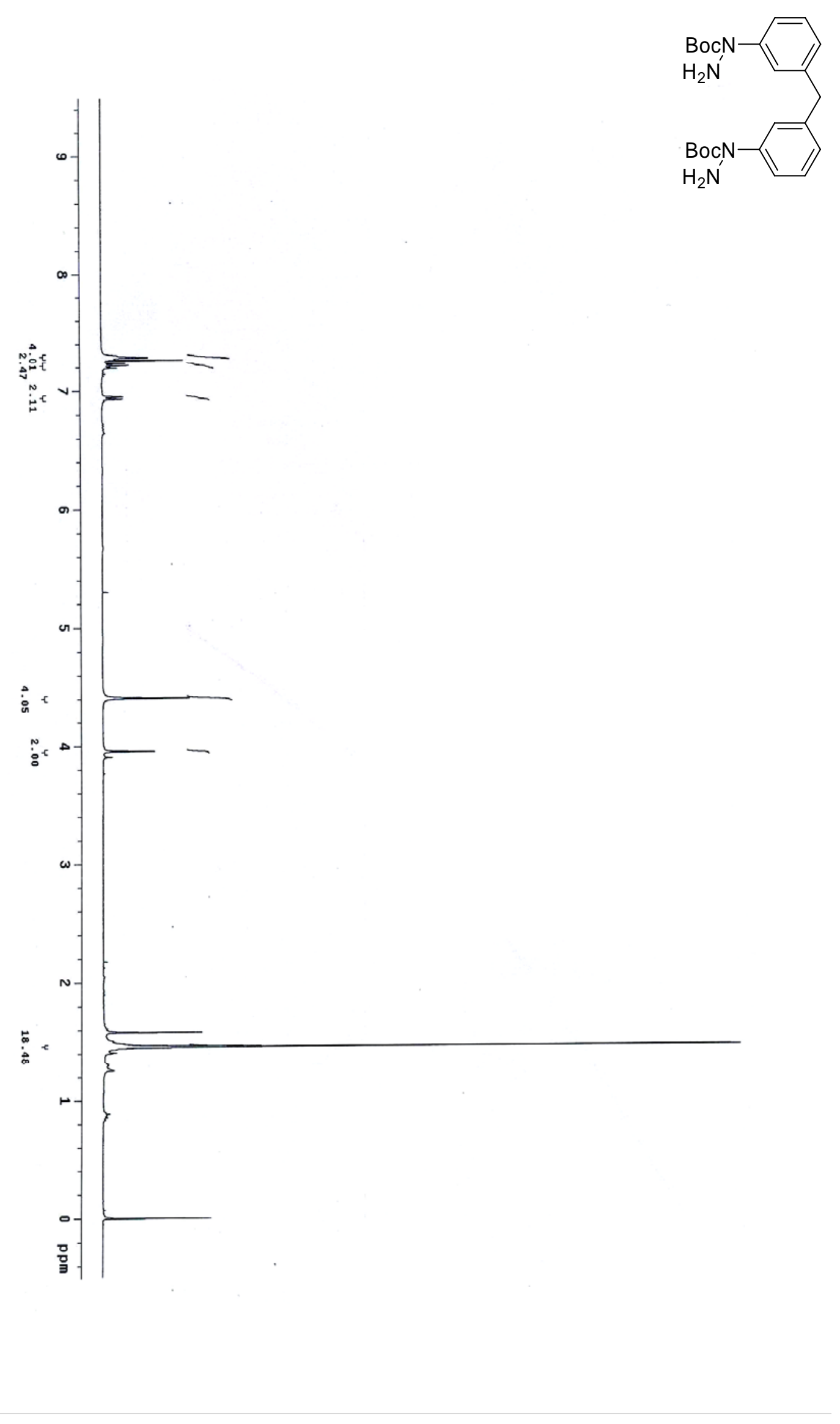




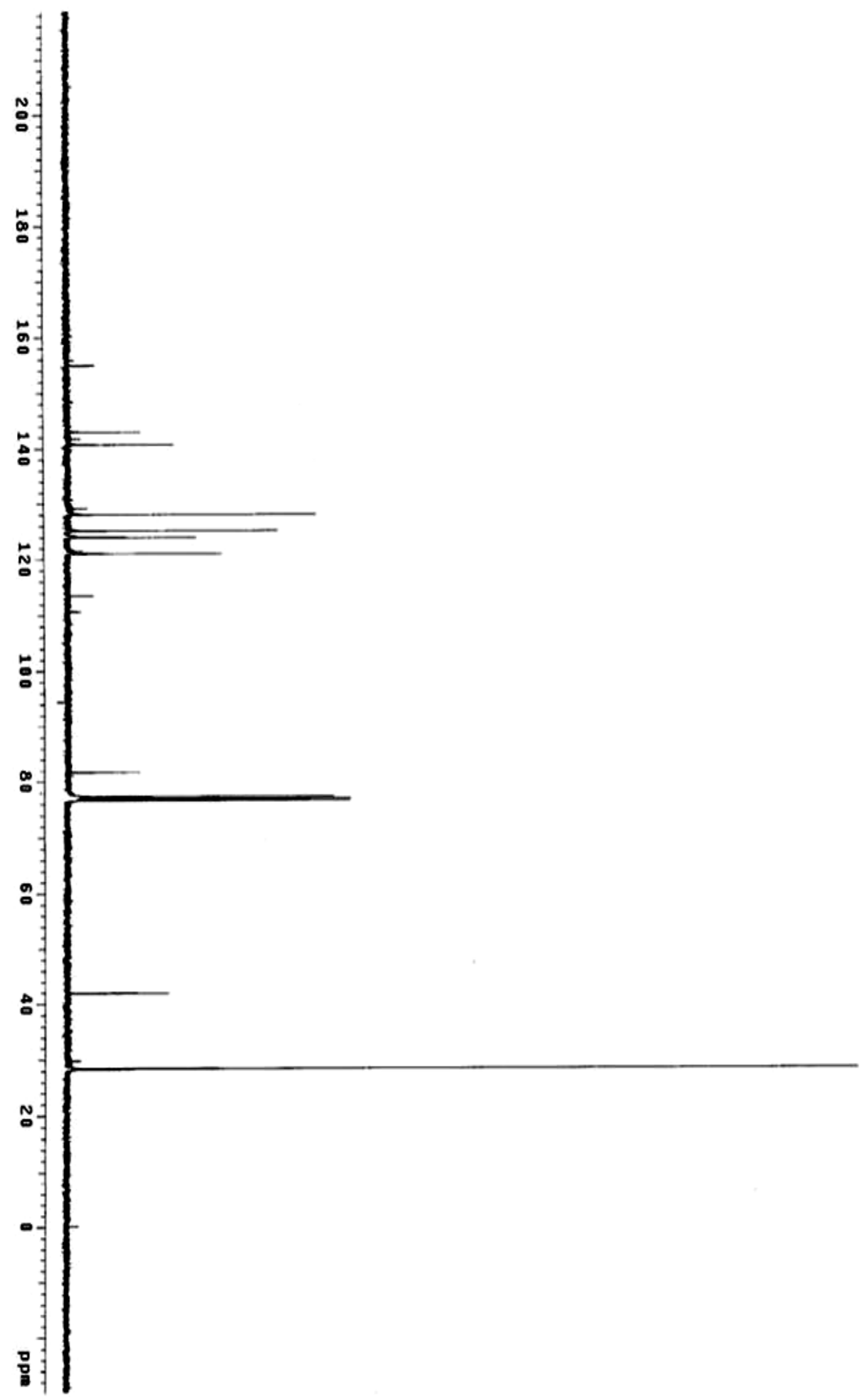




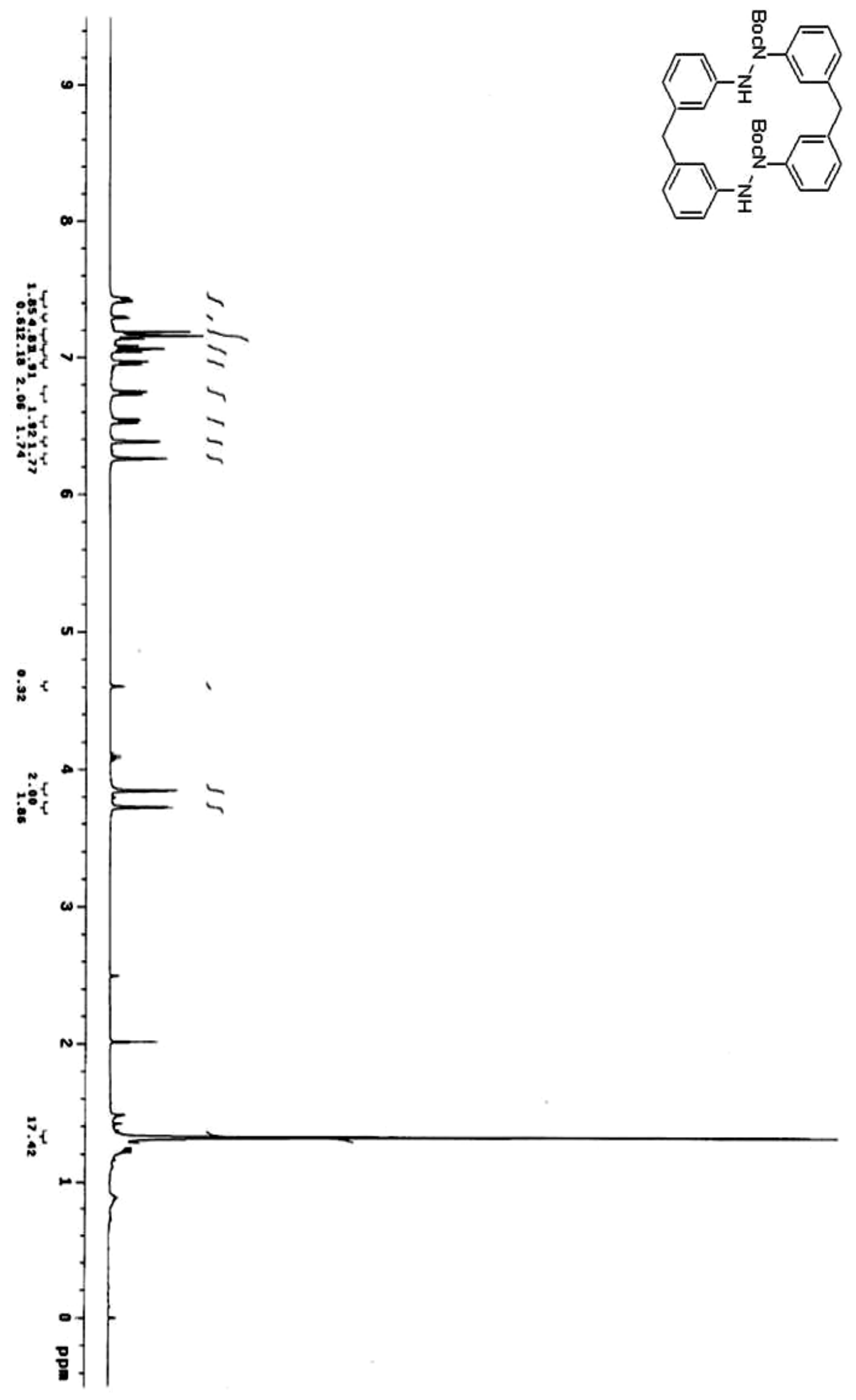




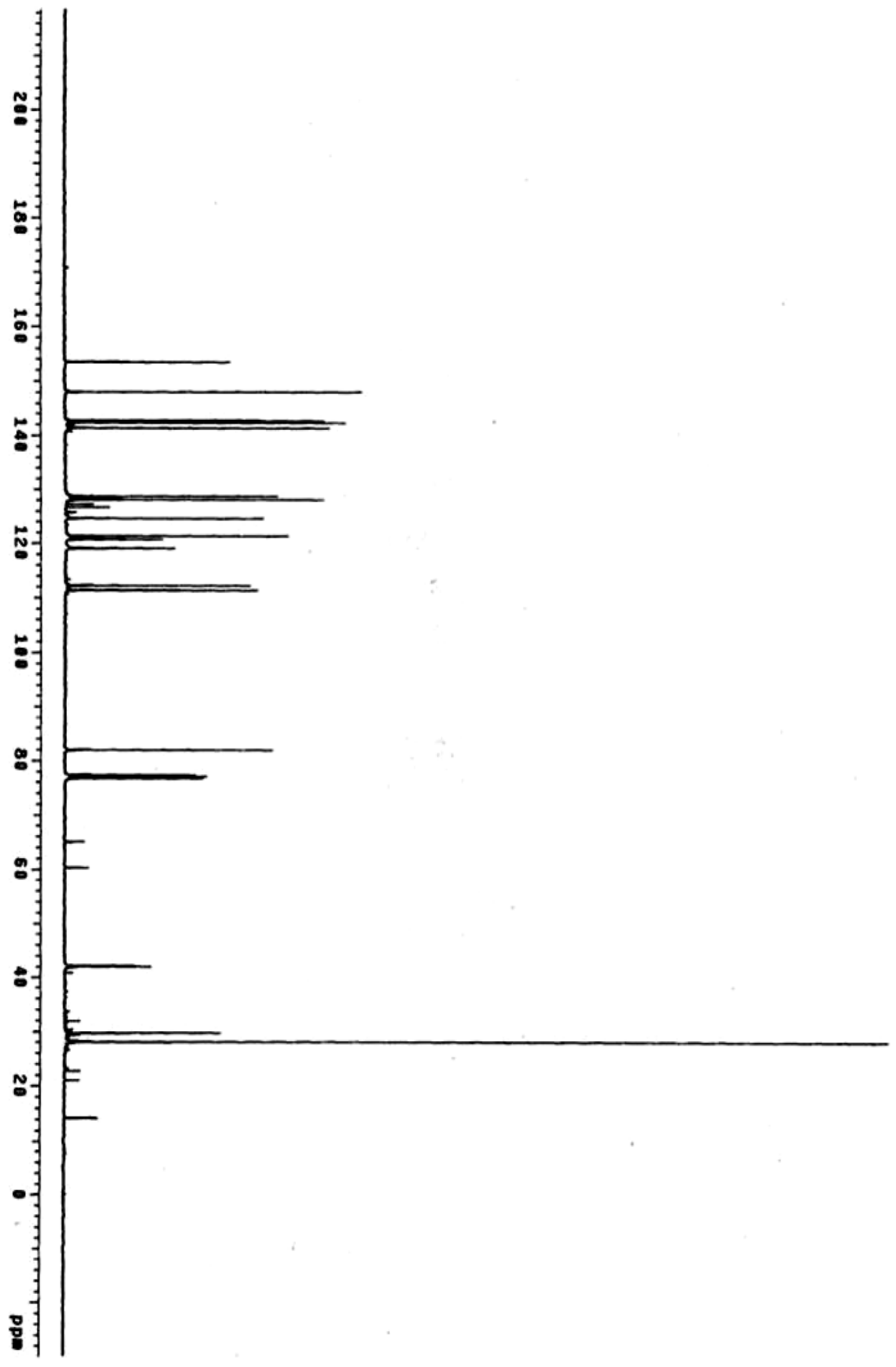




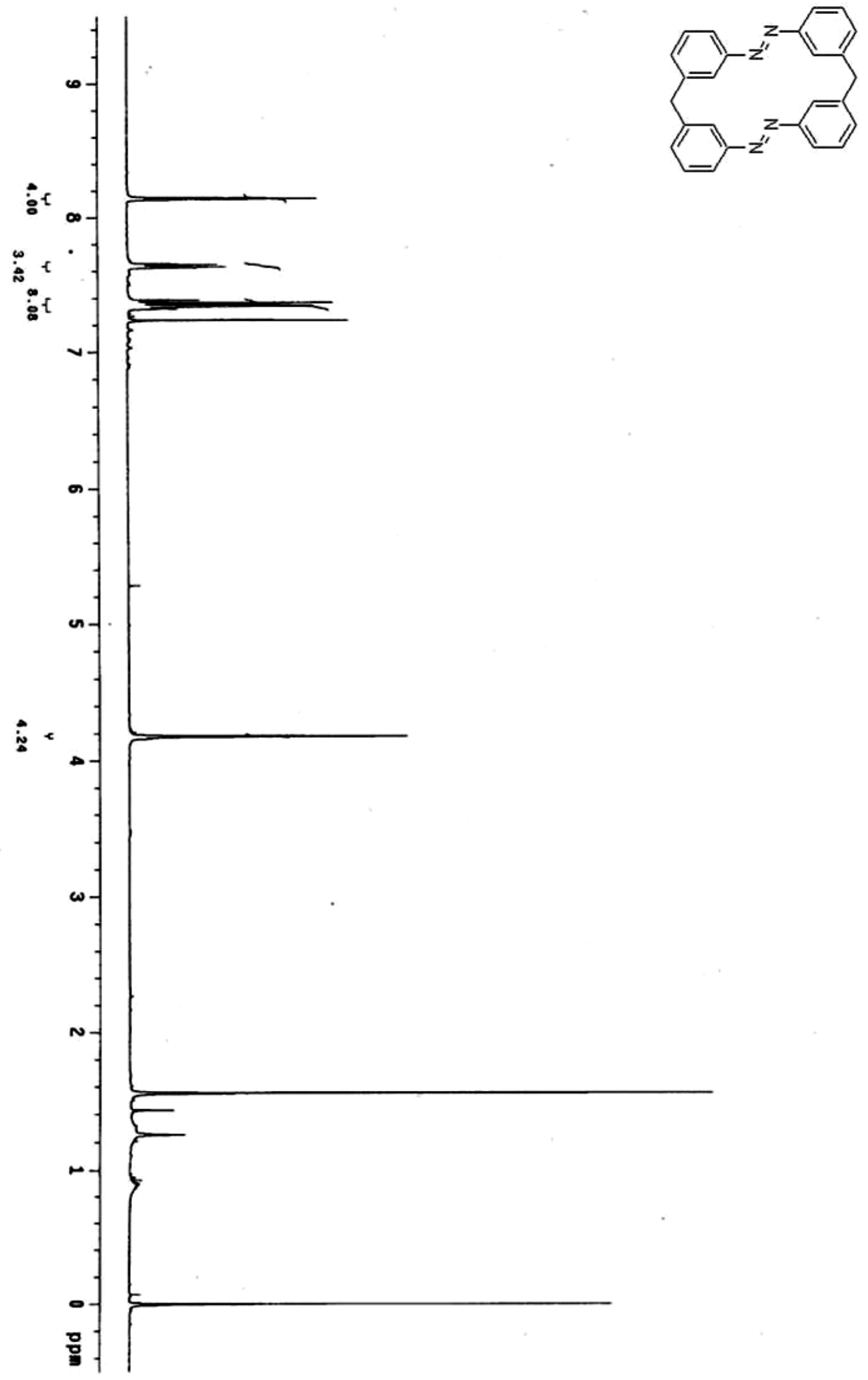

7 


$$
F
$$




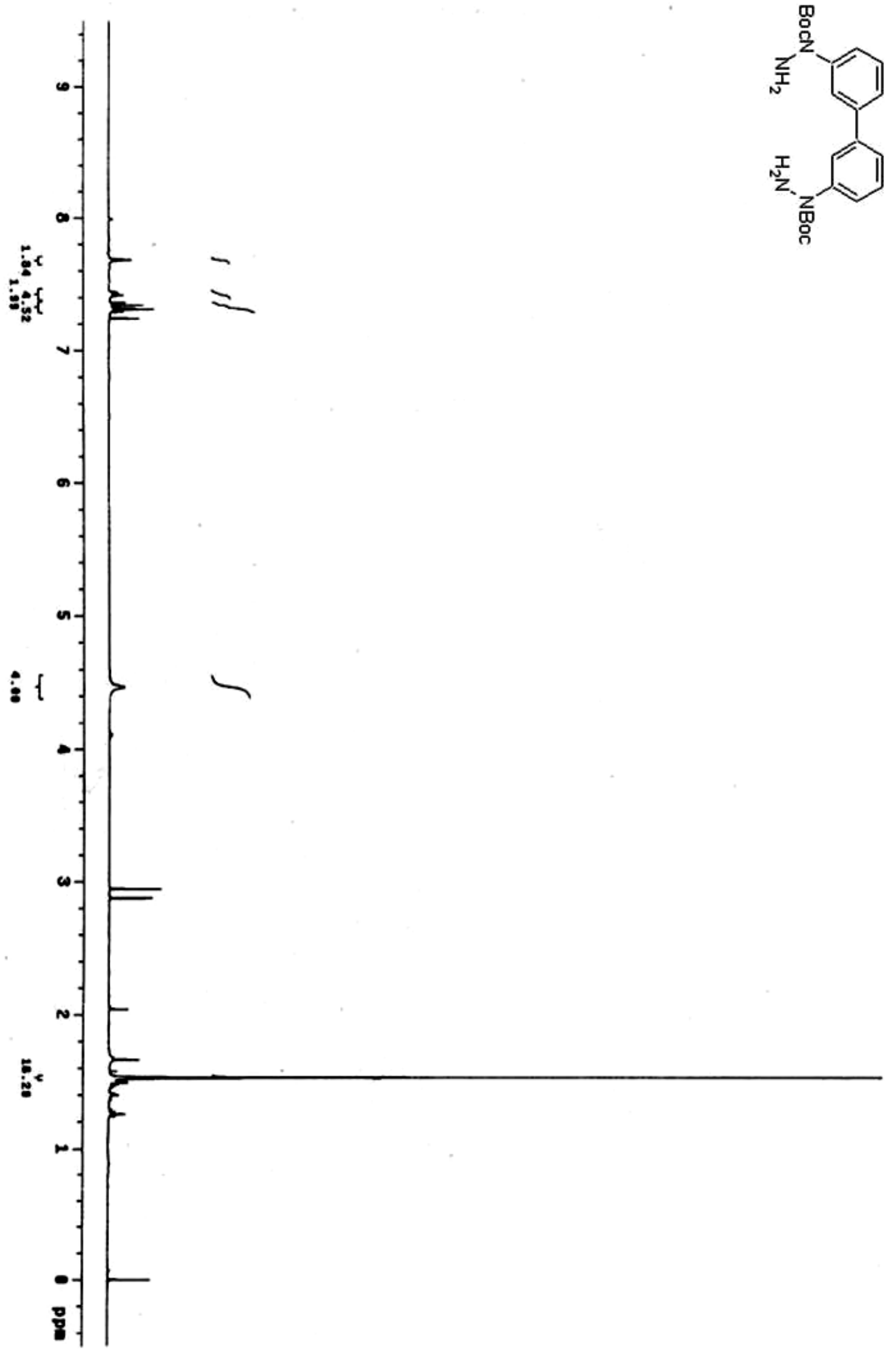




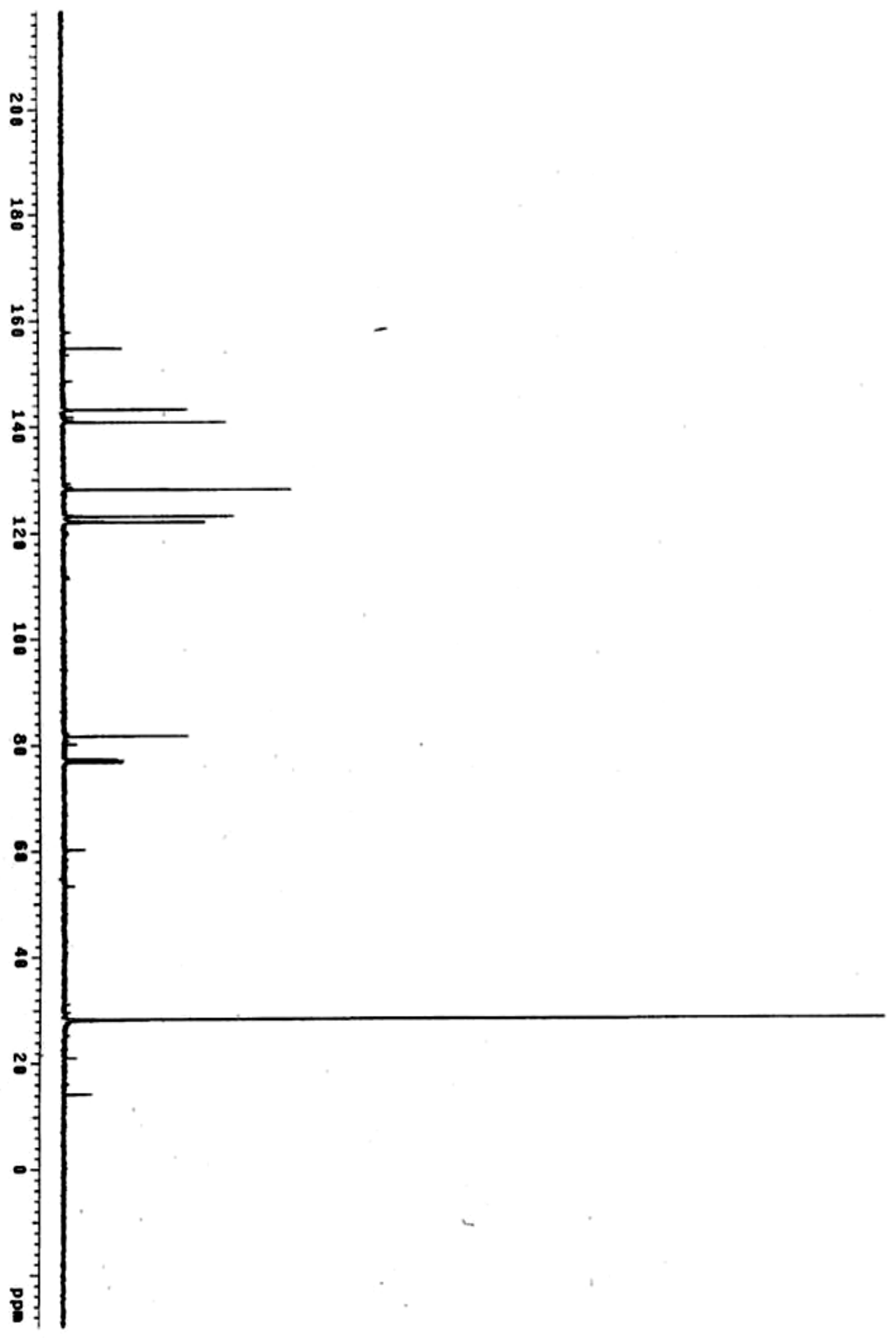




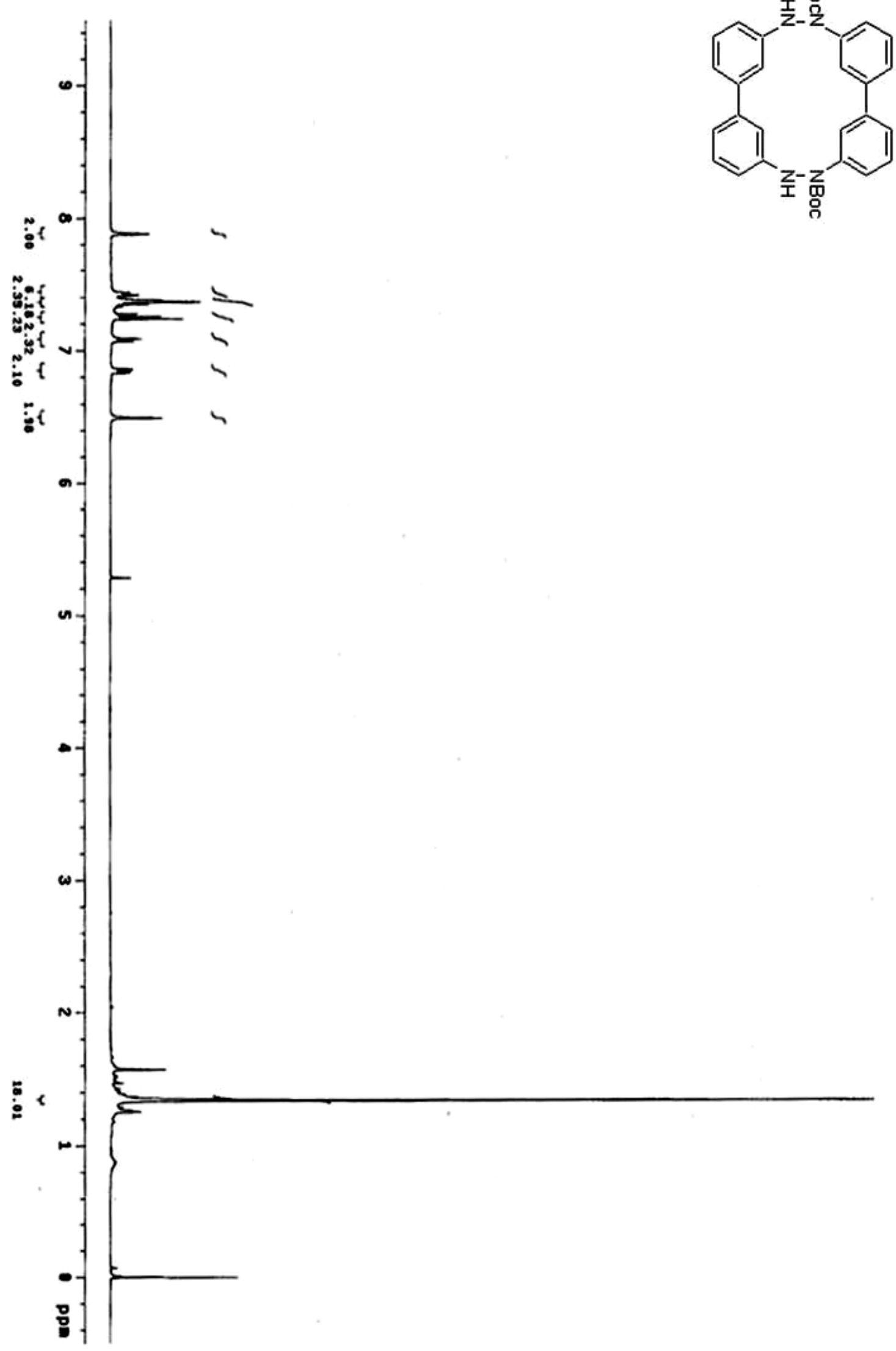




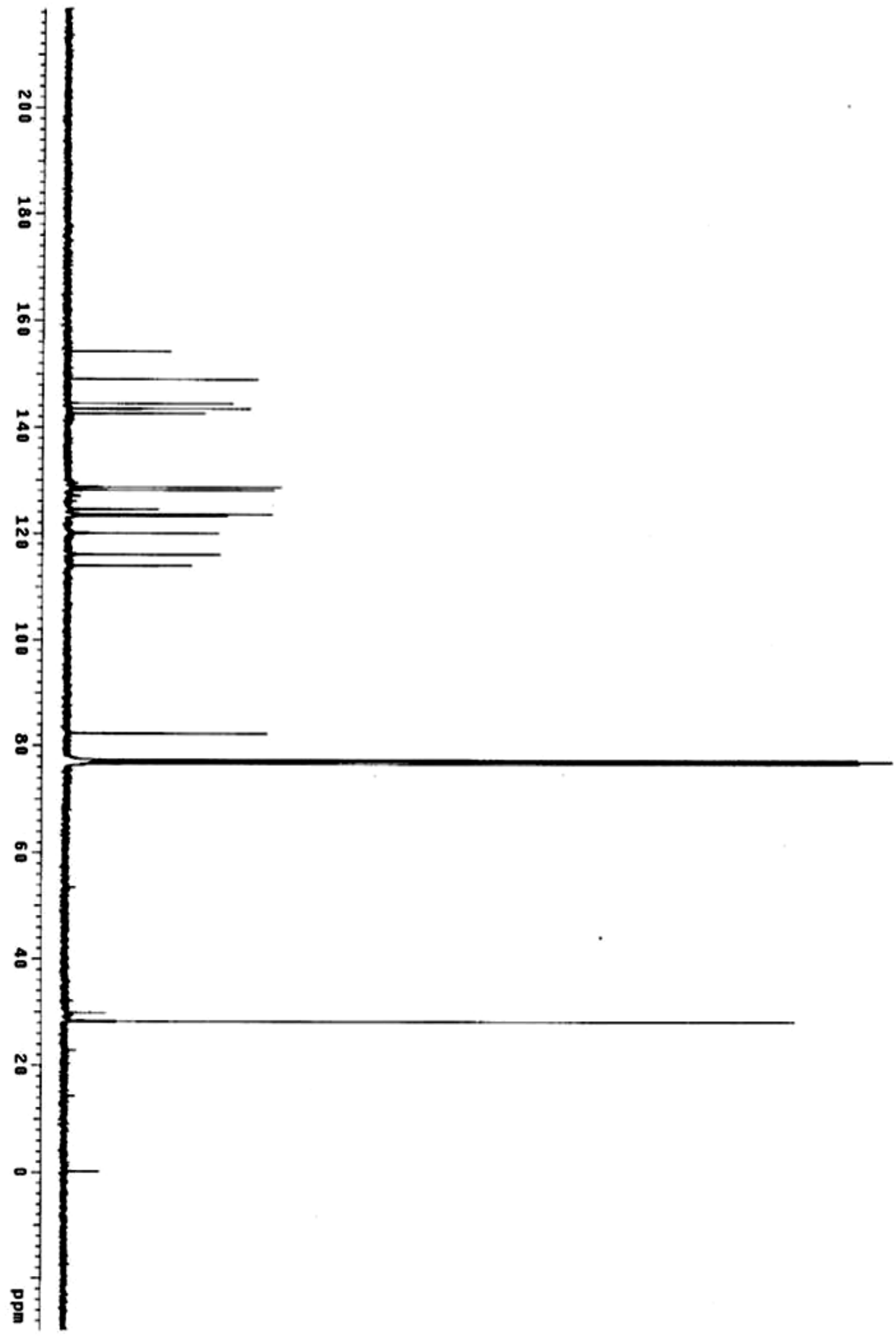




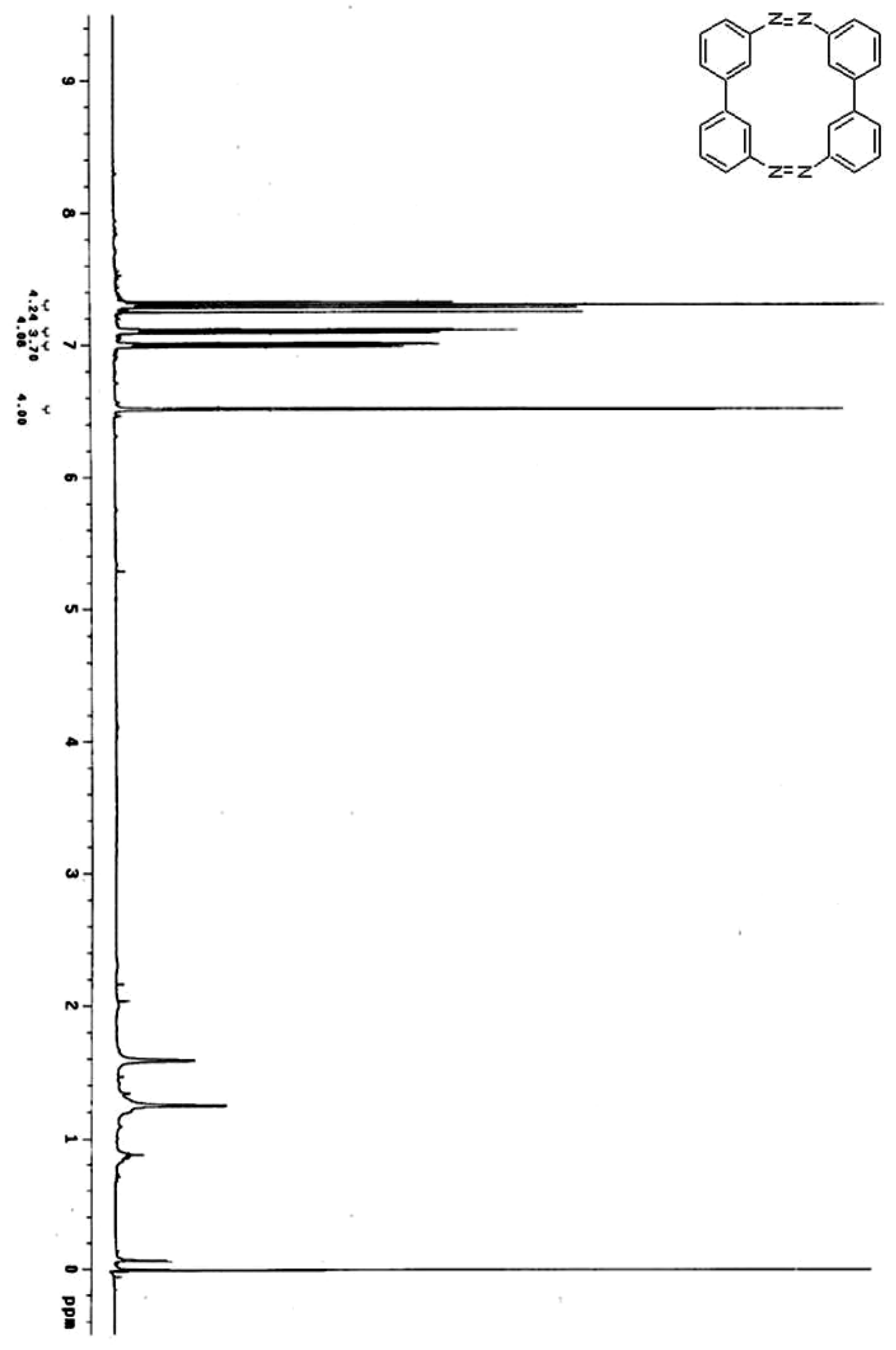




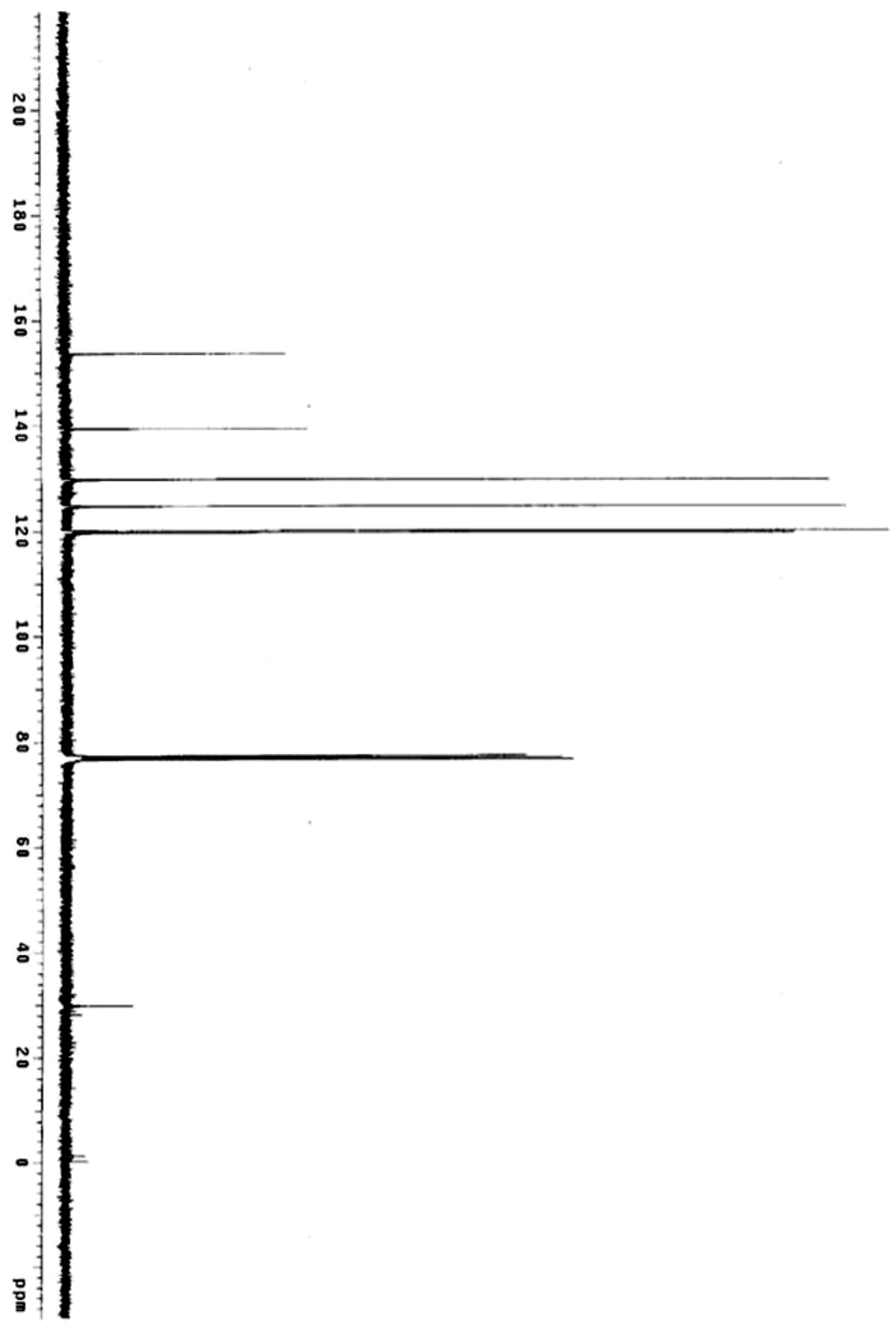




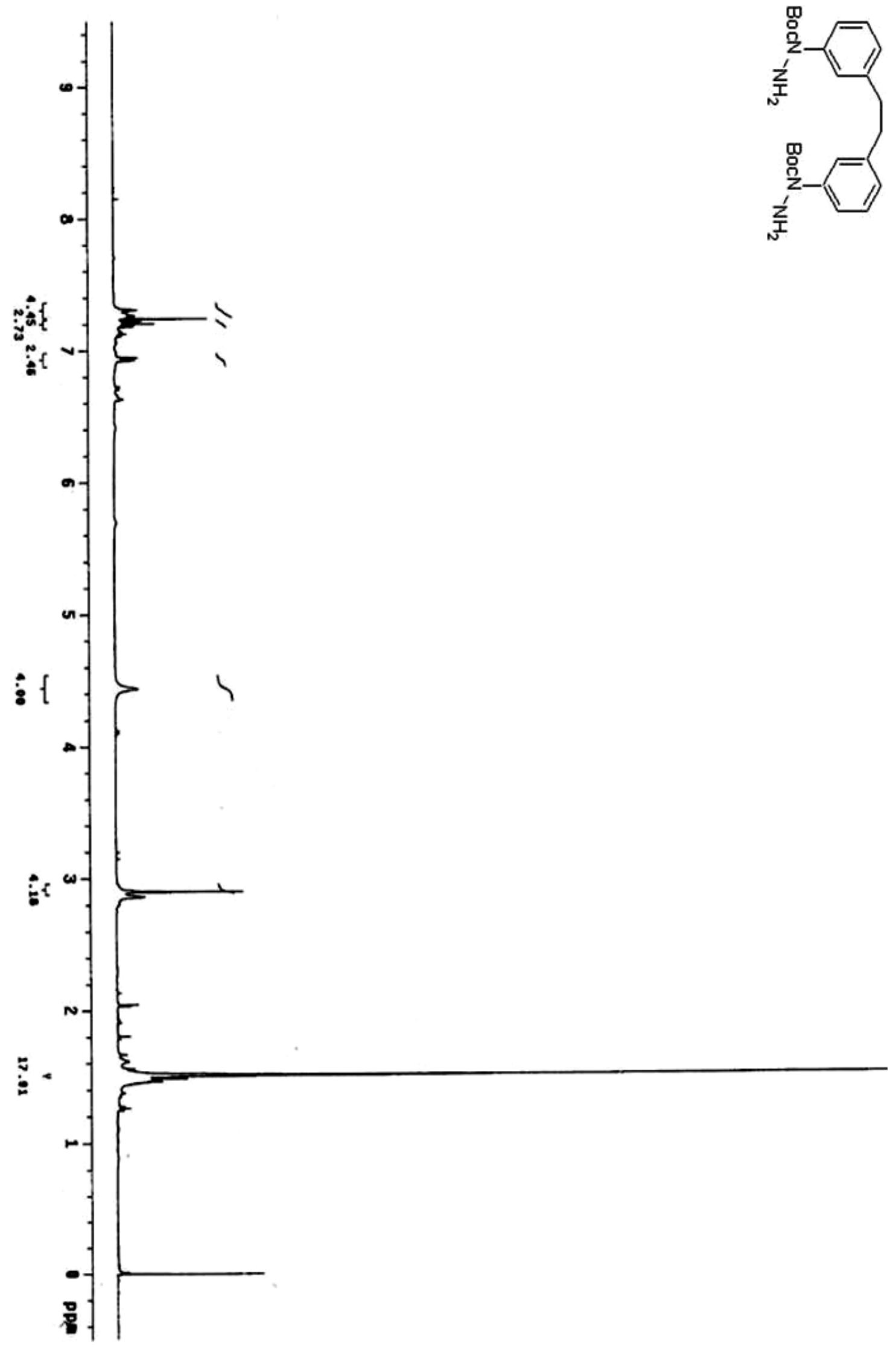




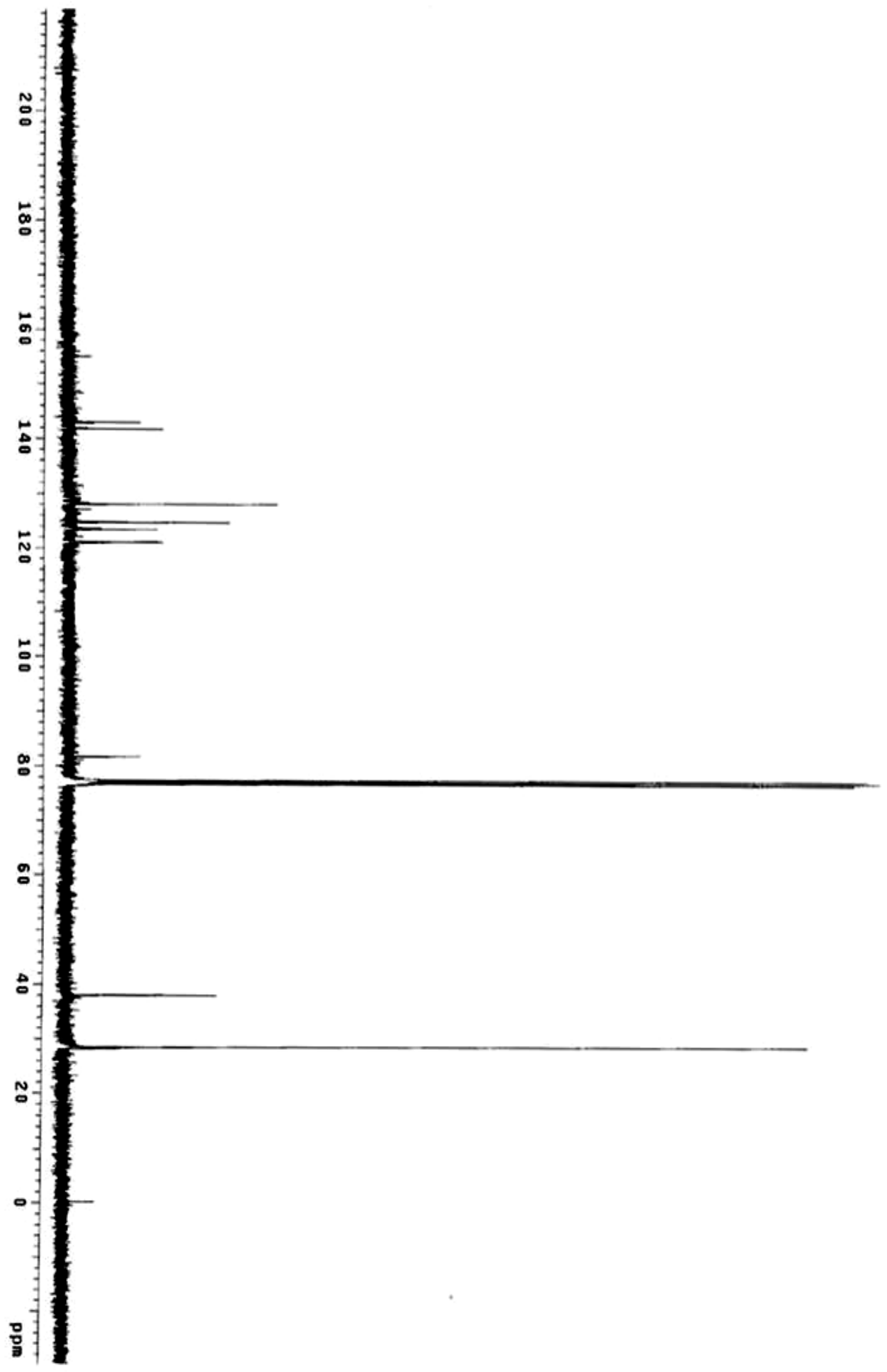




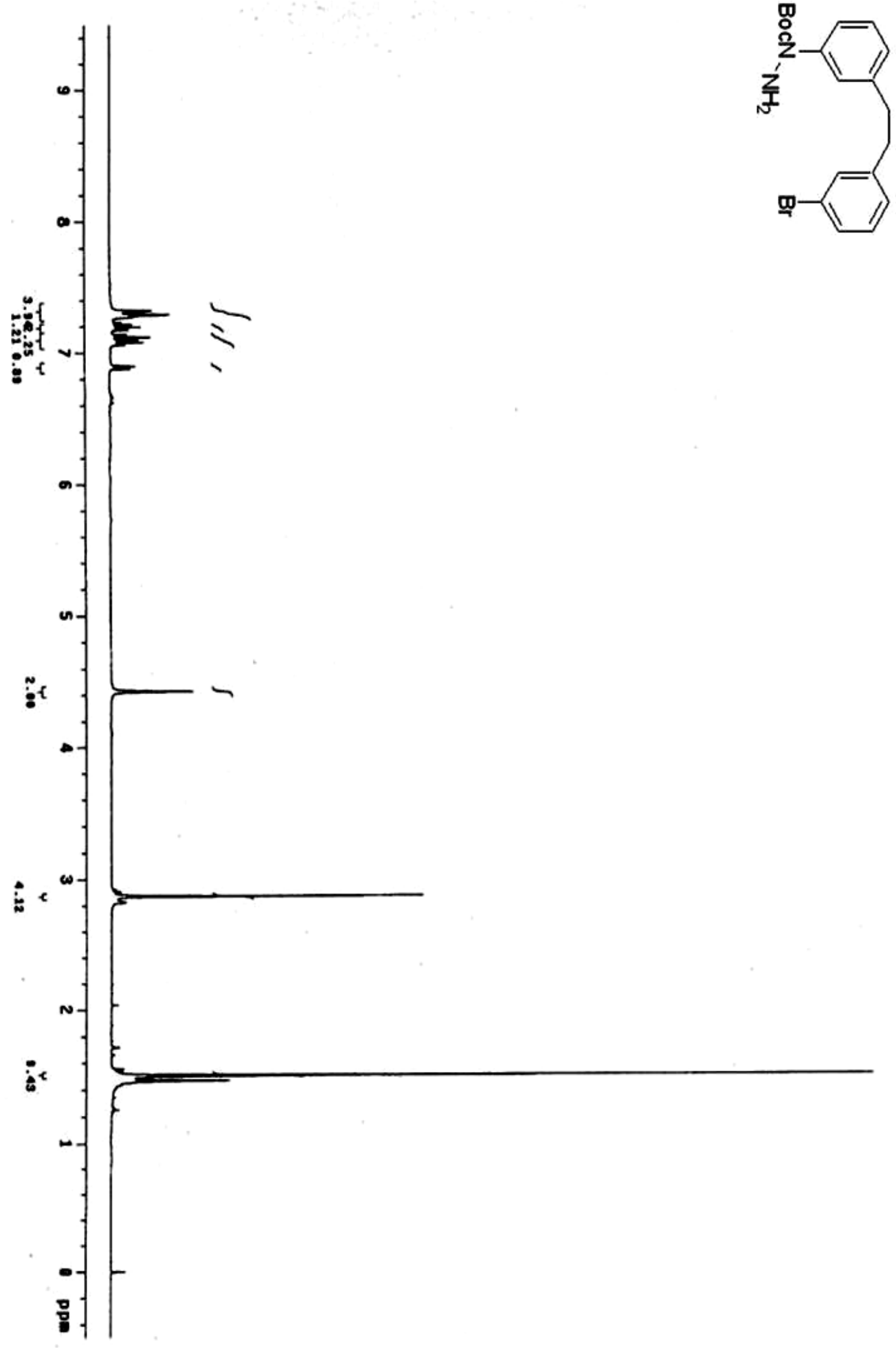




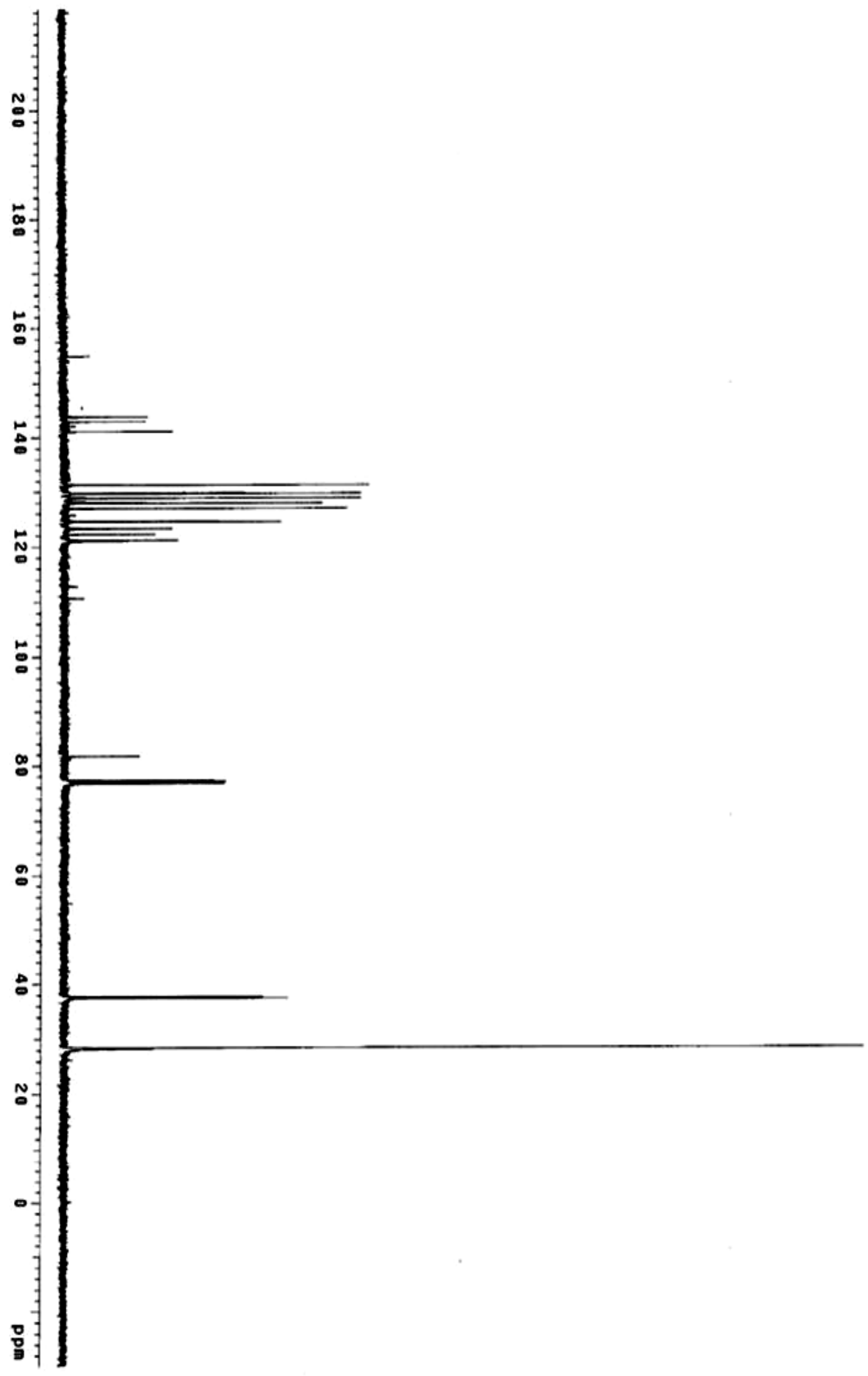




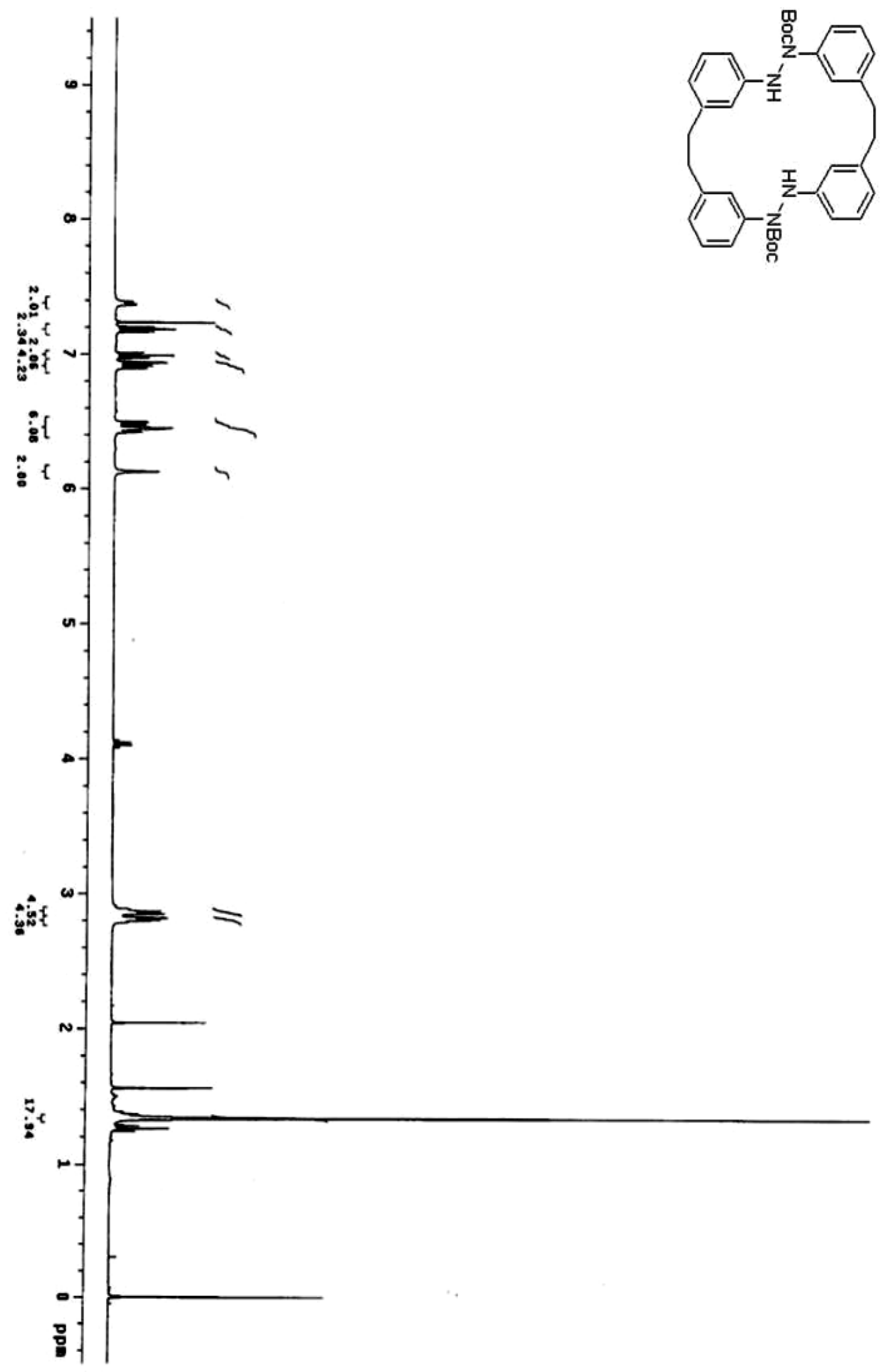




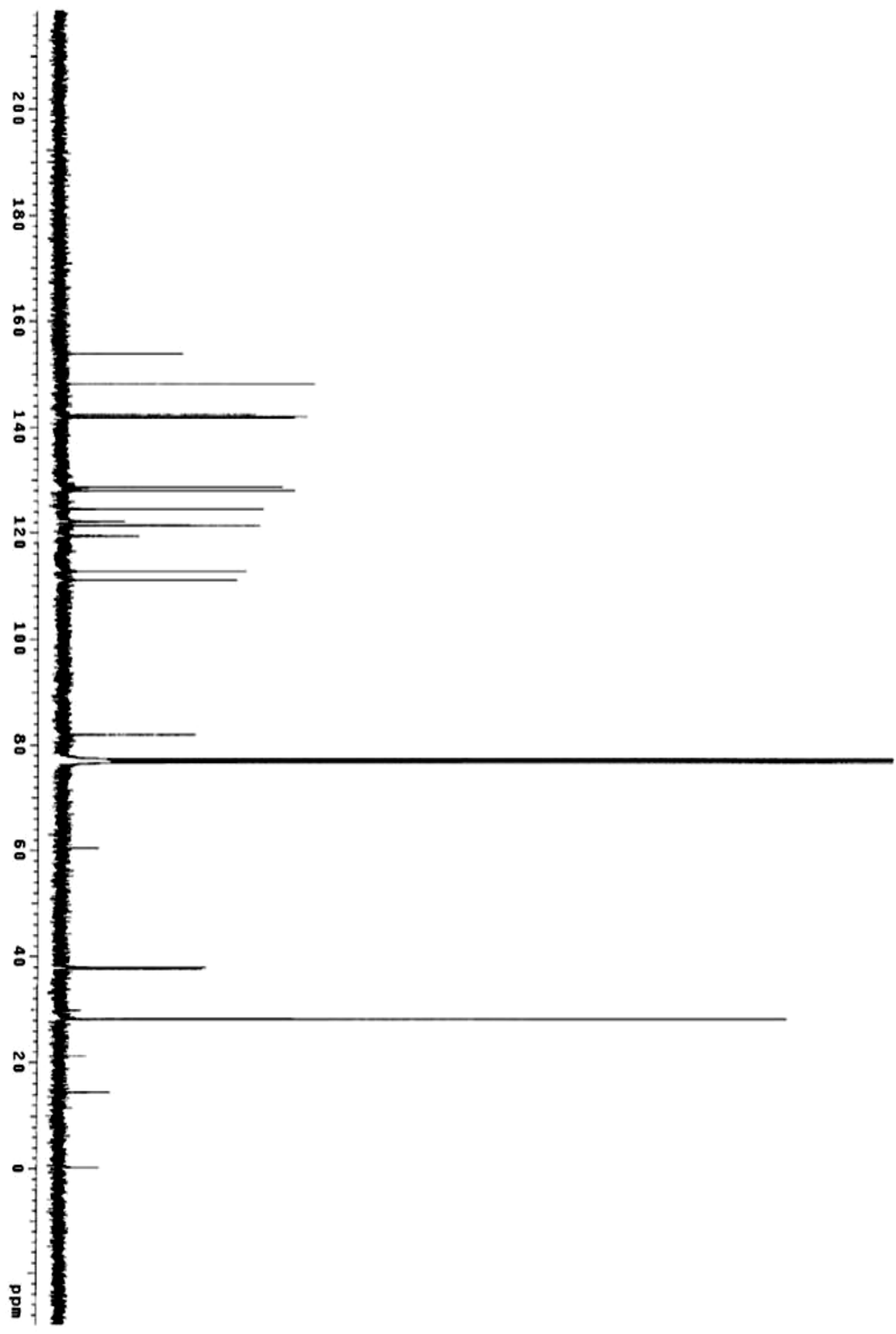




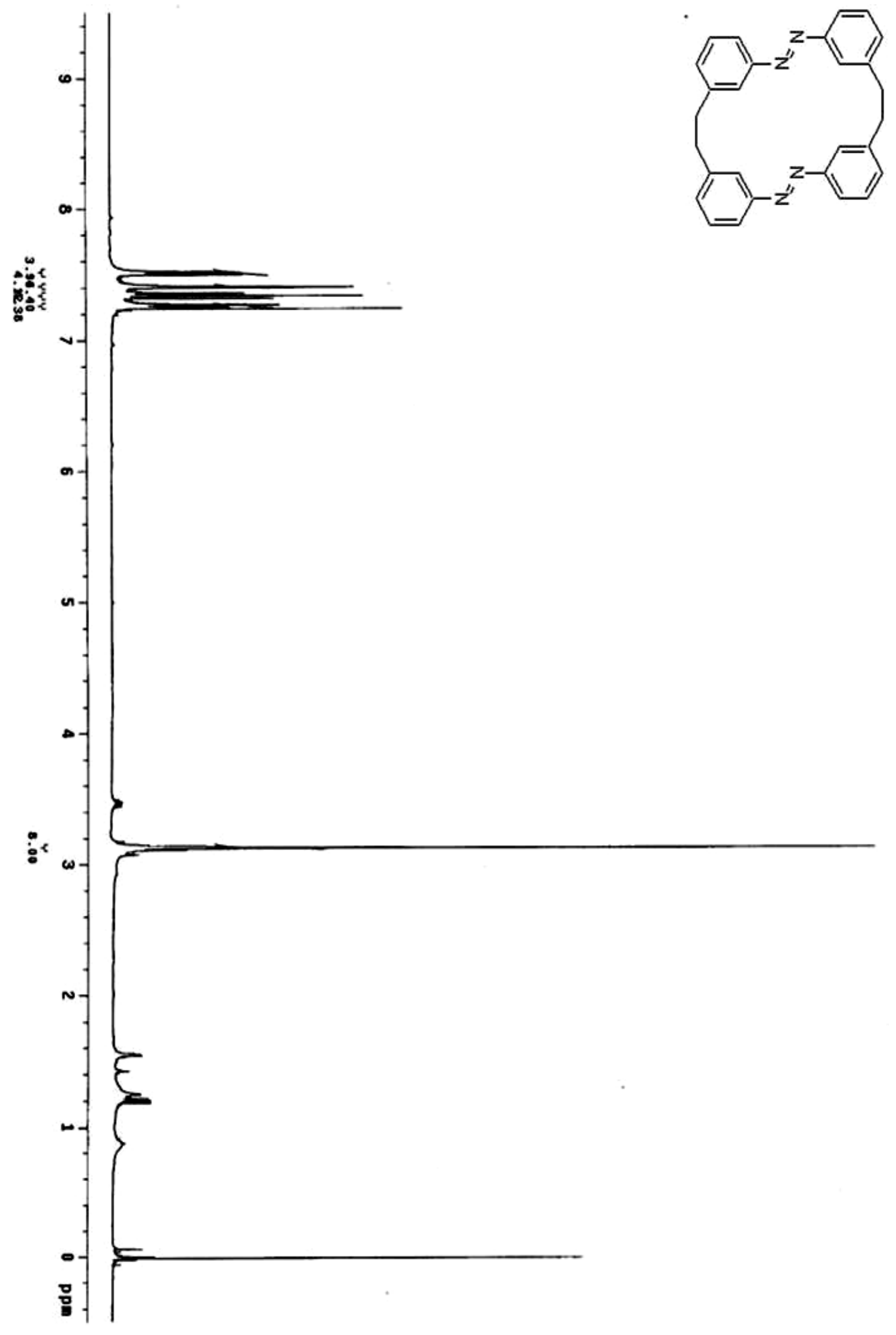




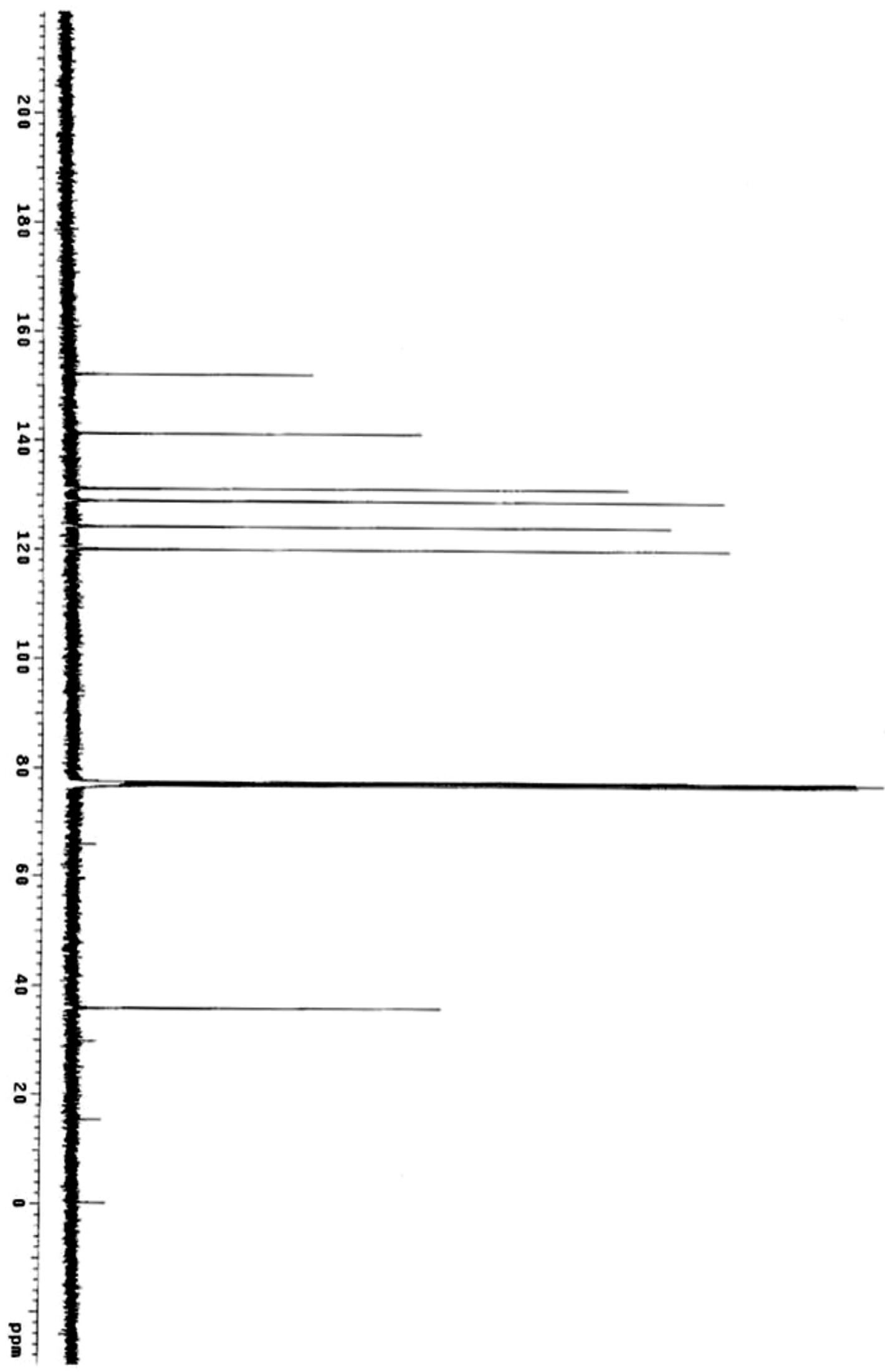




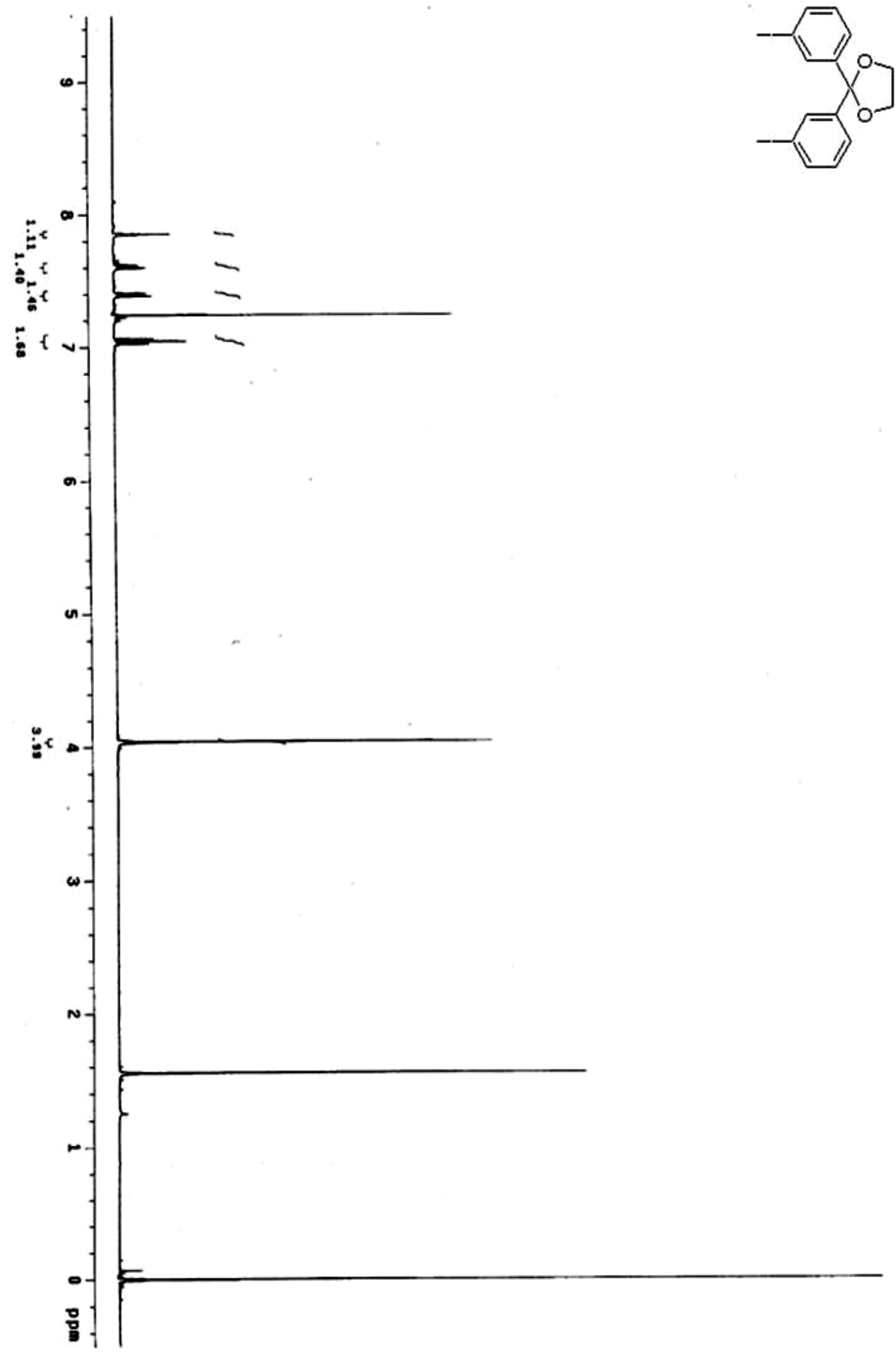




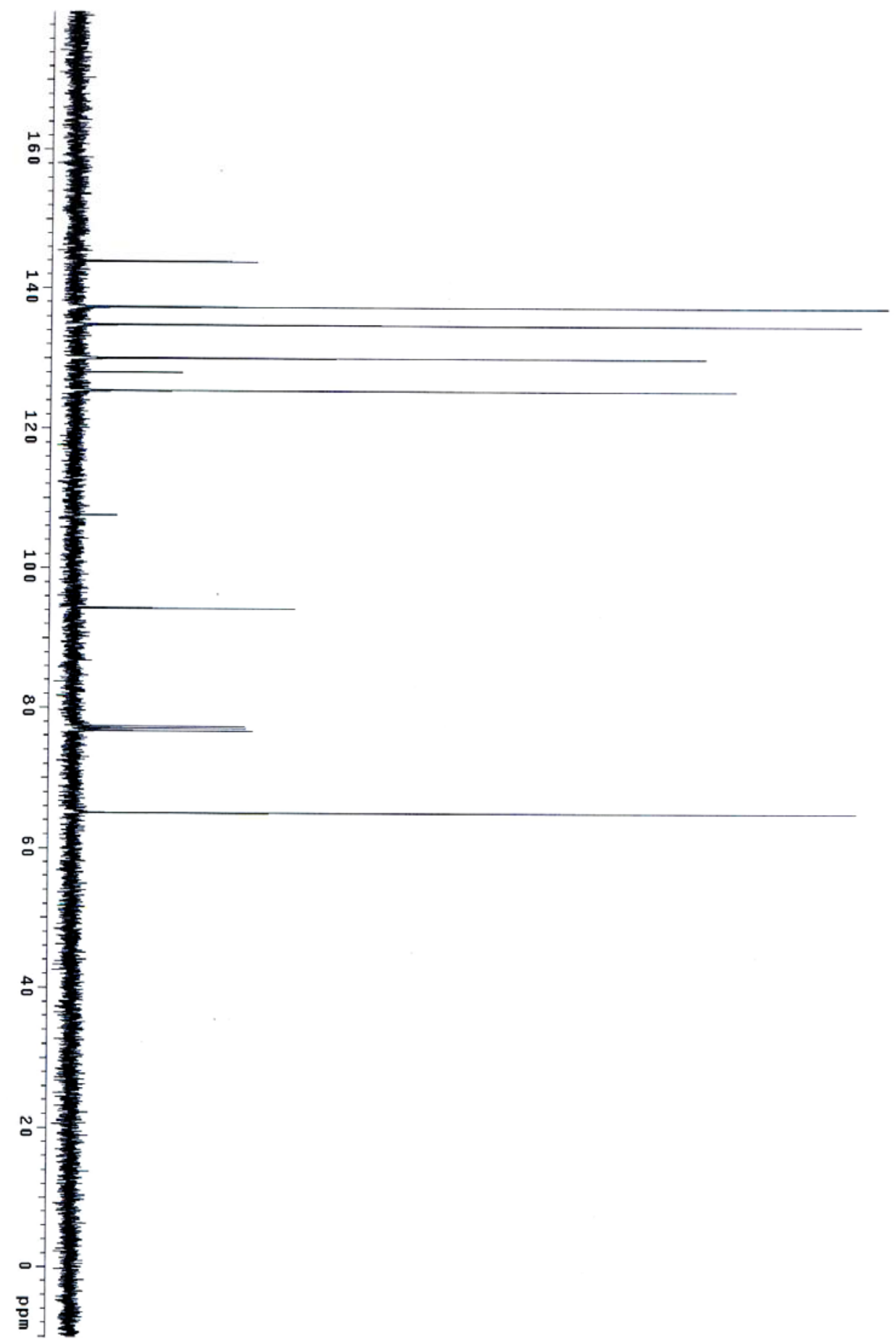




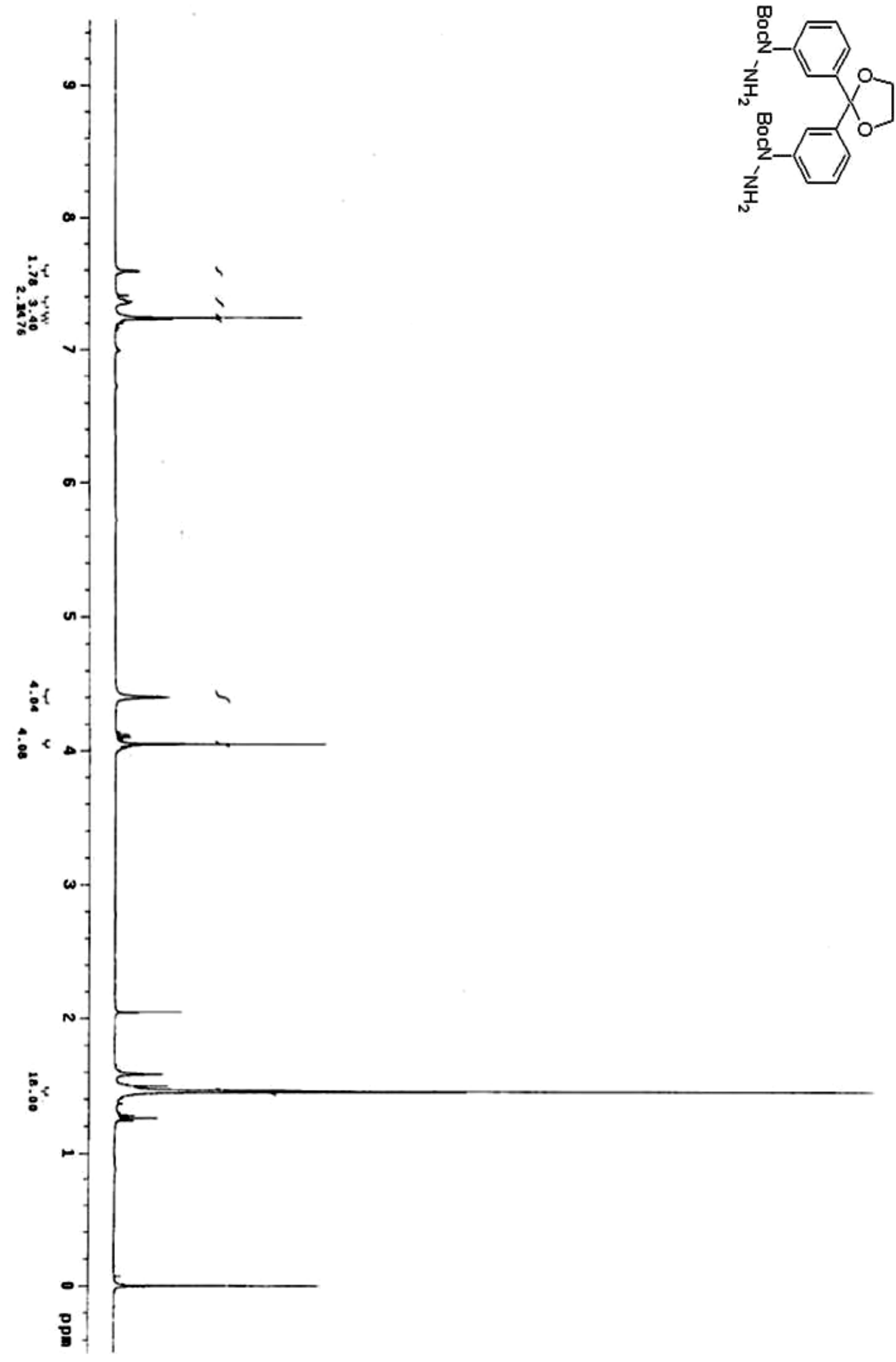




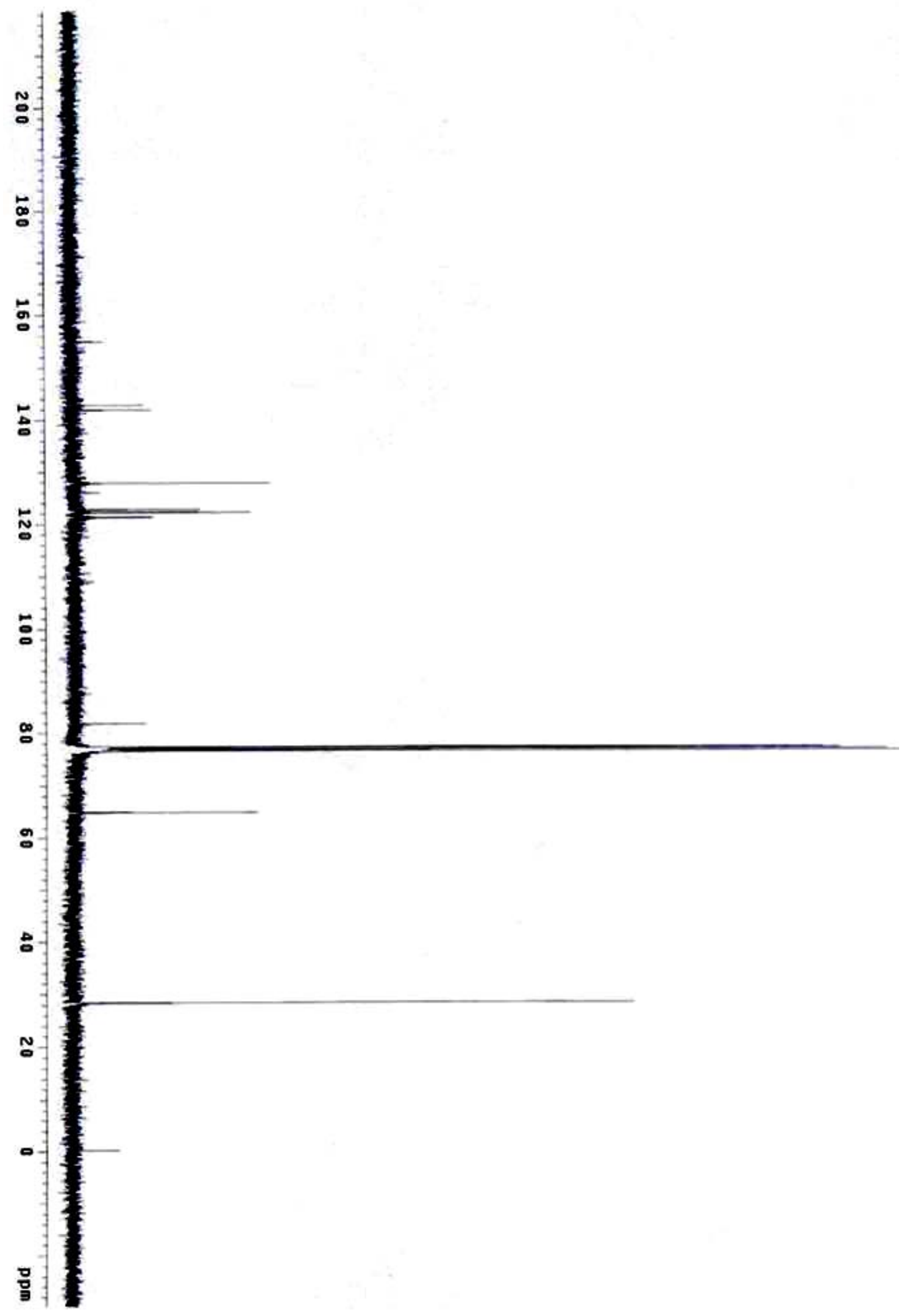




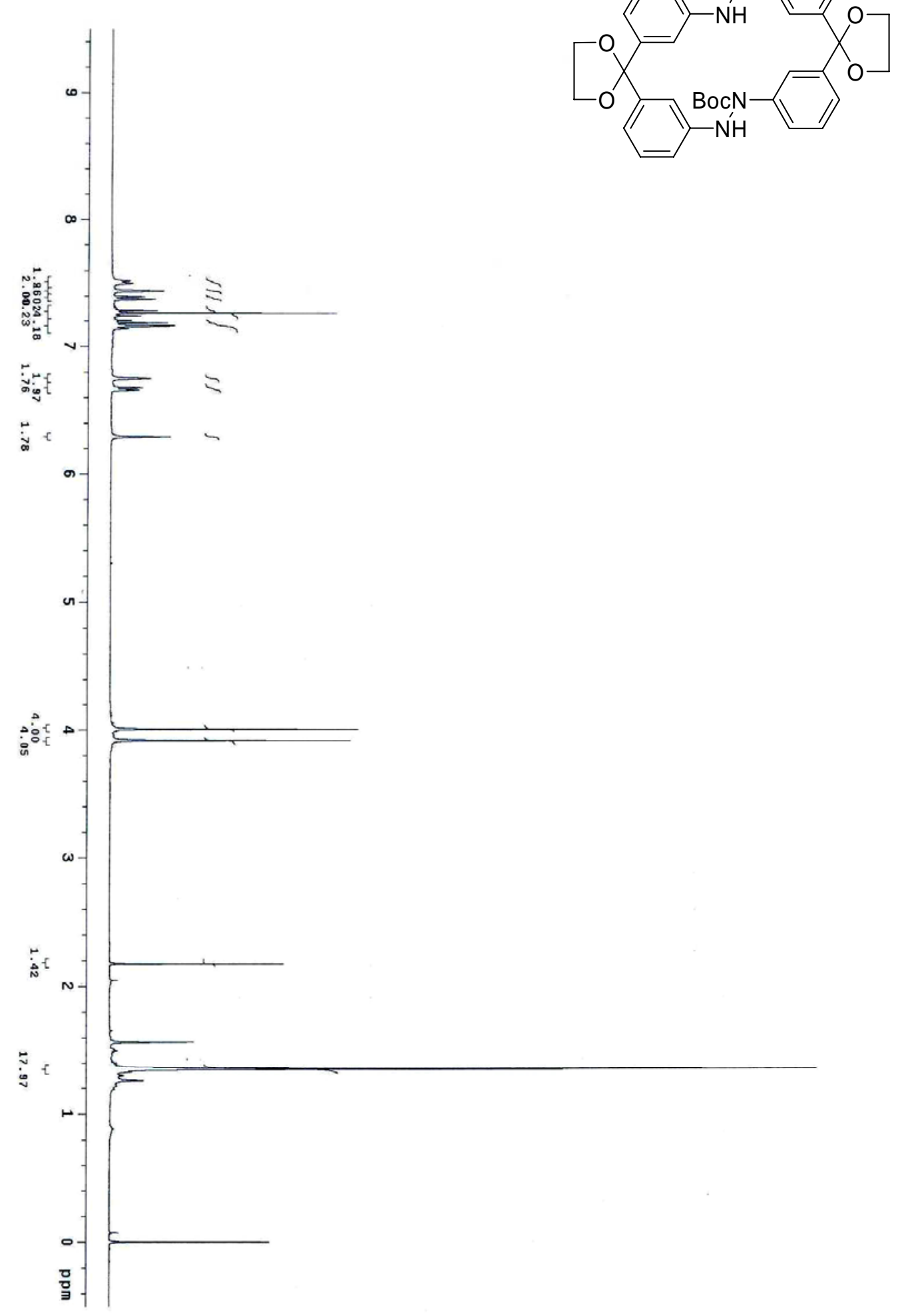




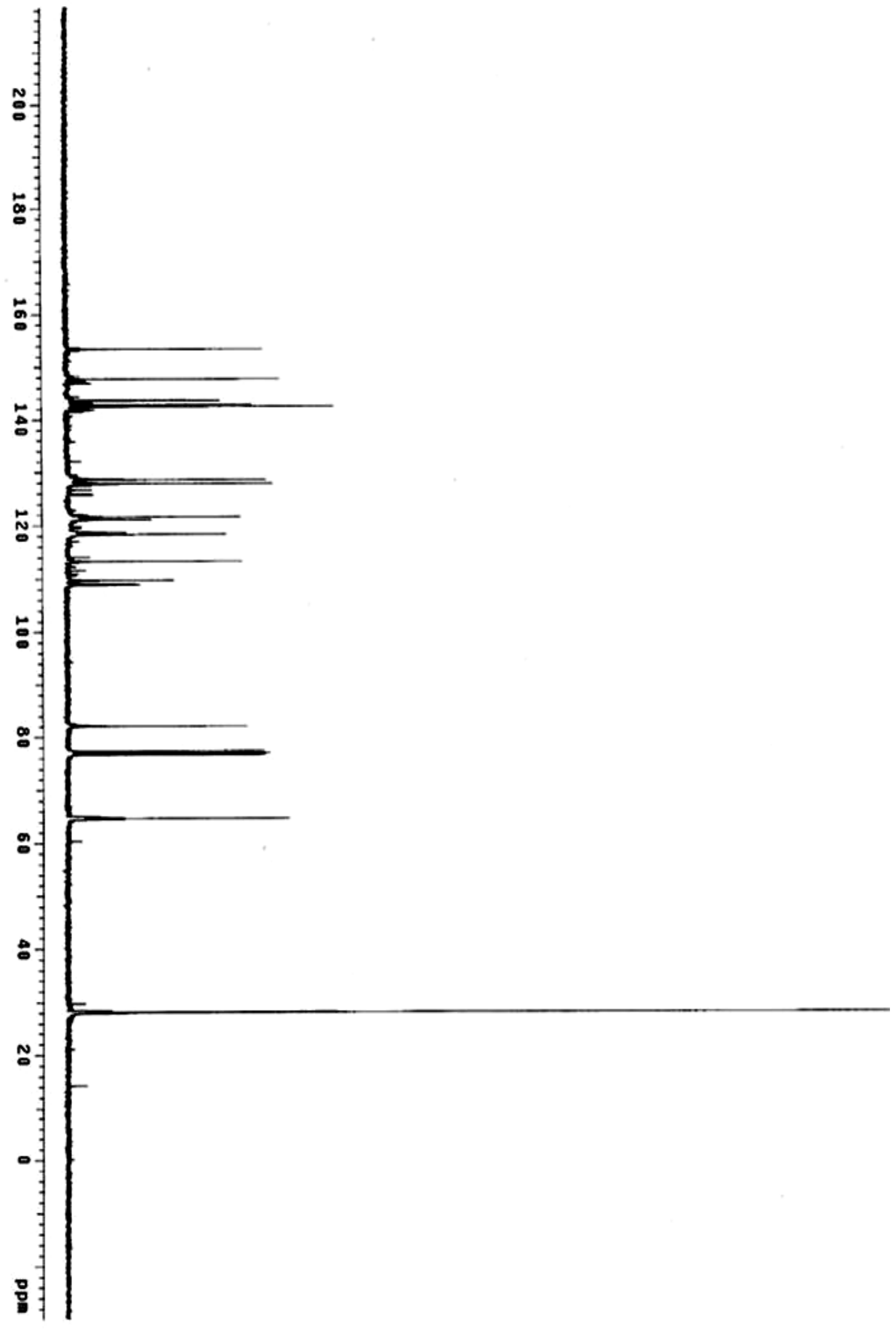




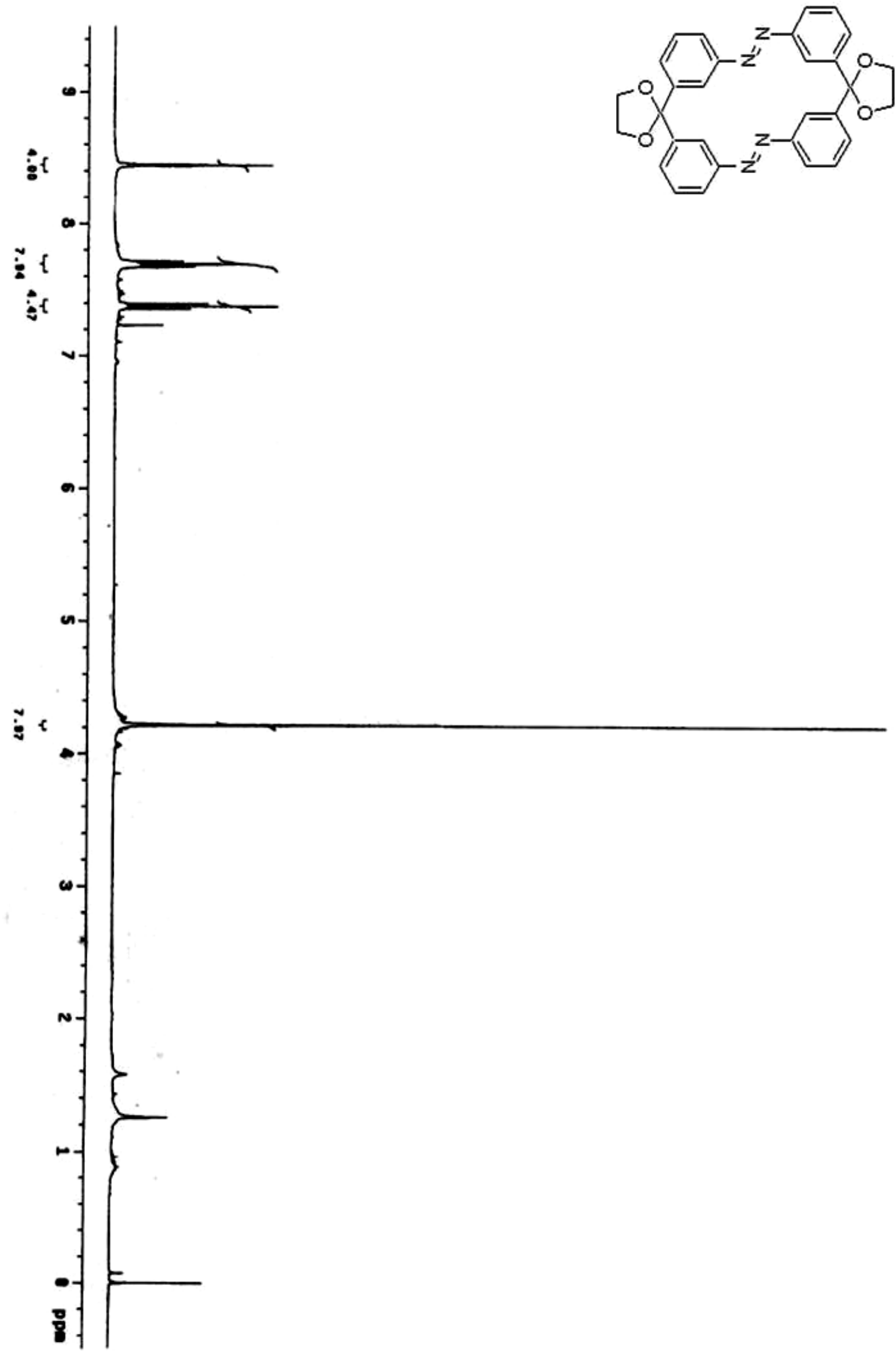




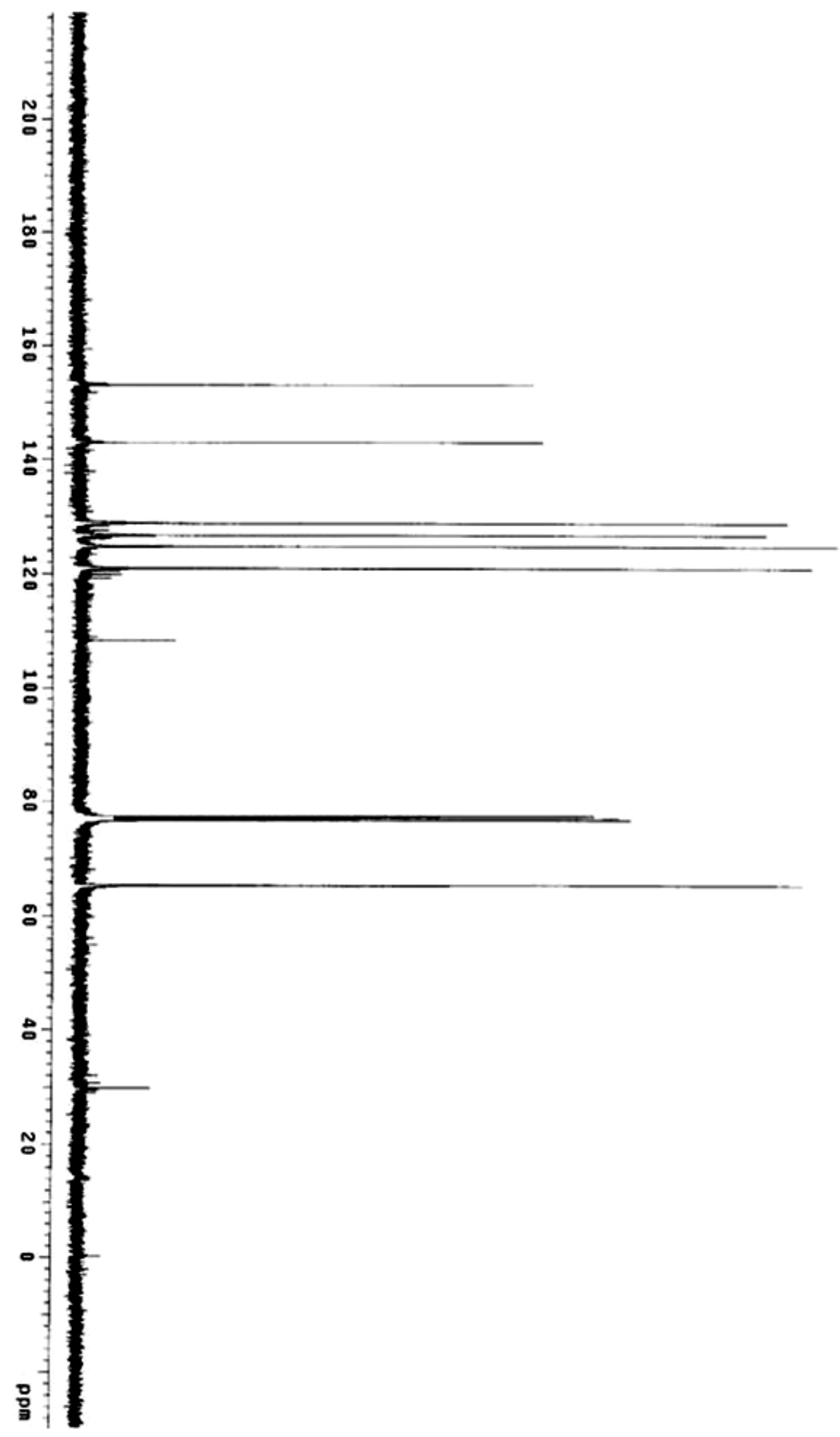




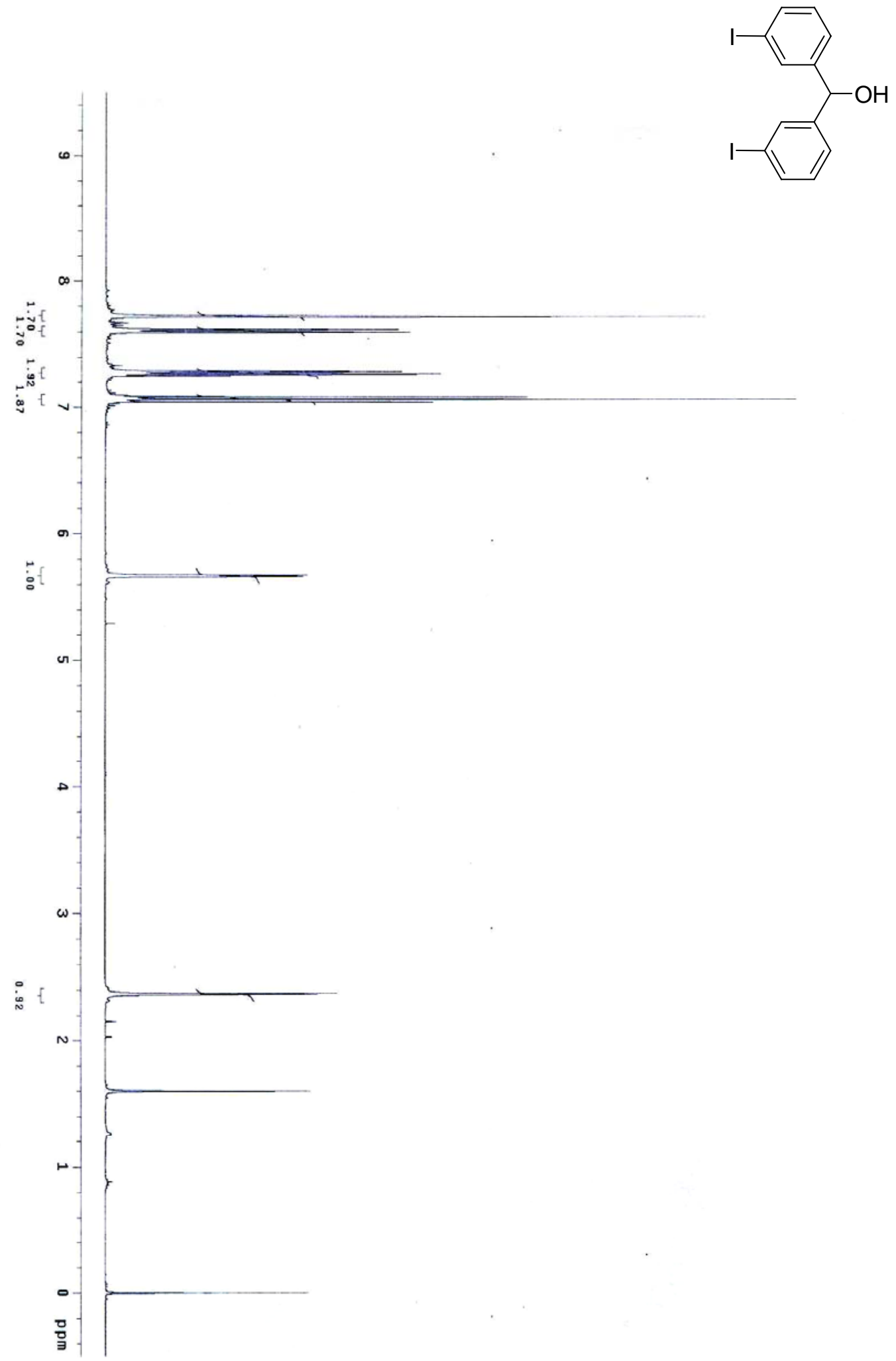




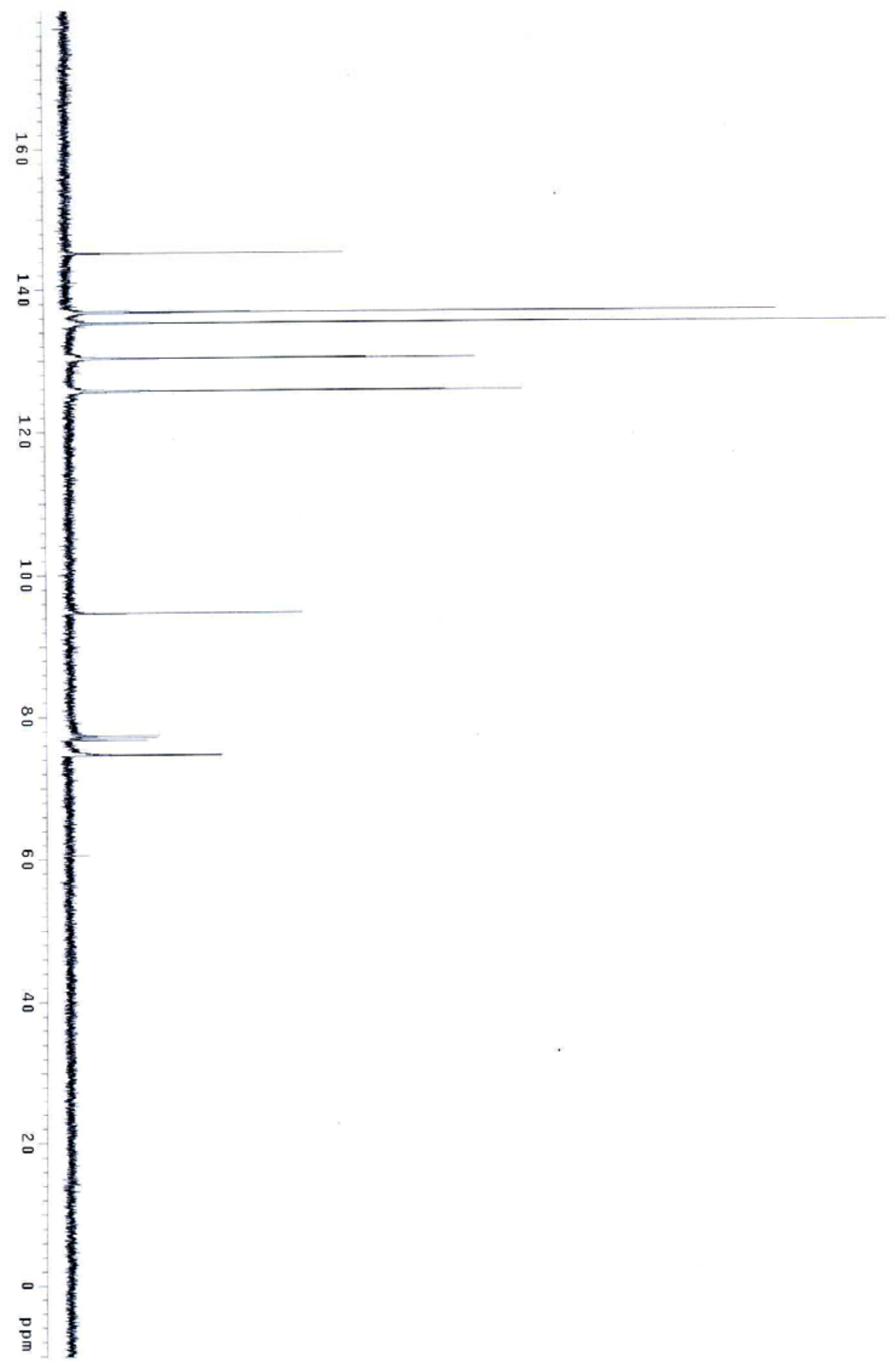



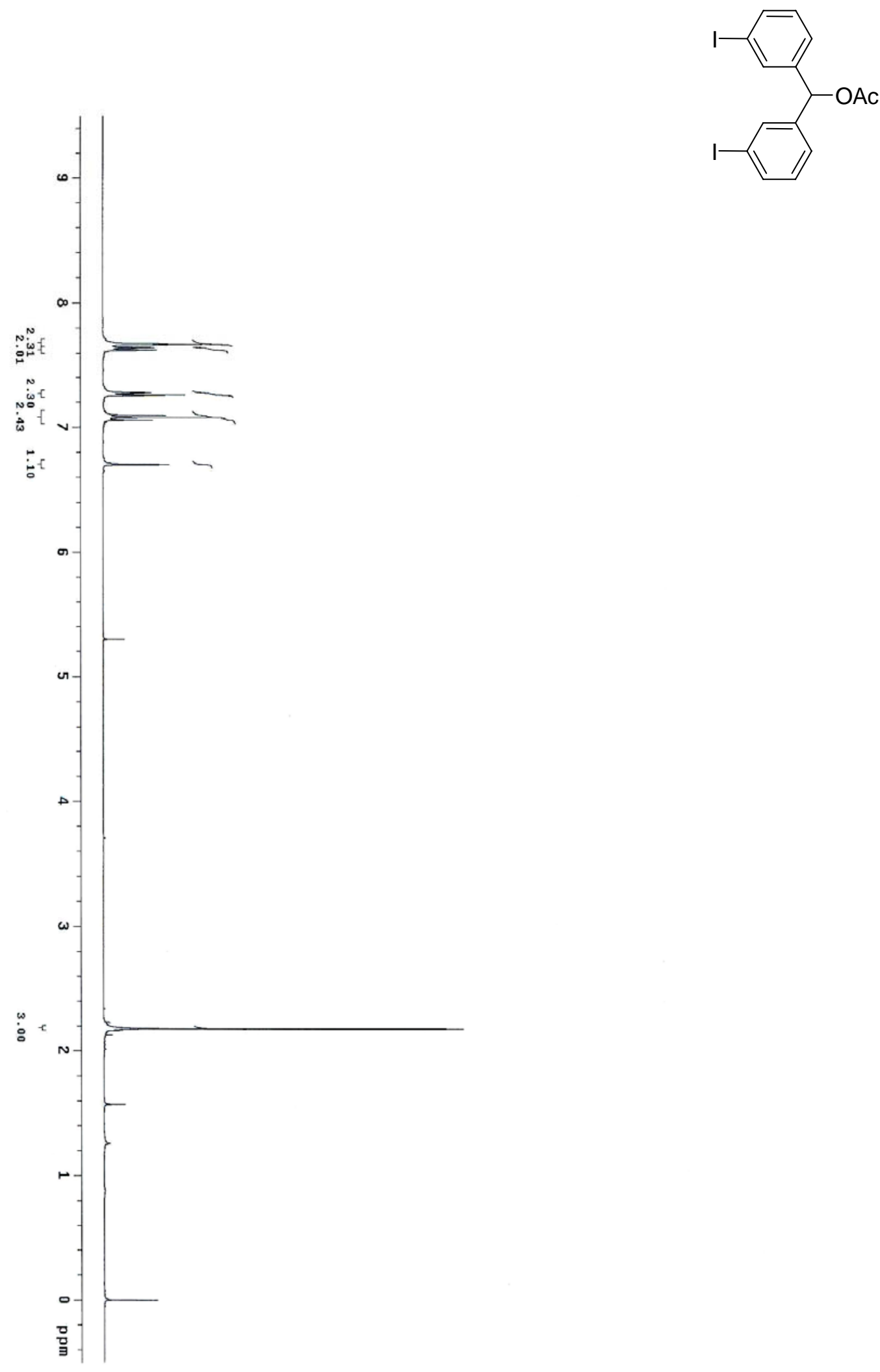


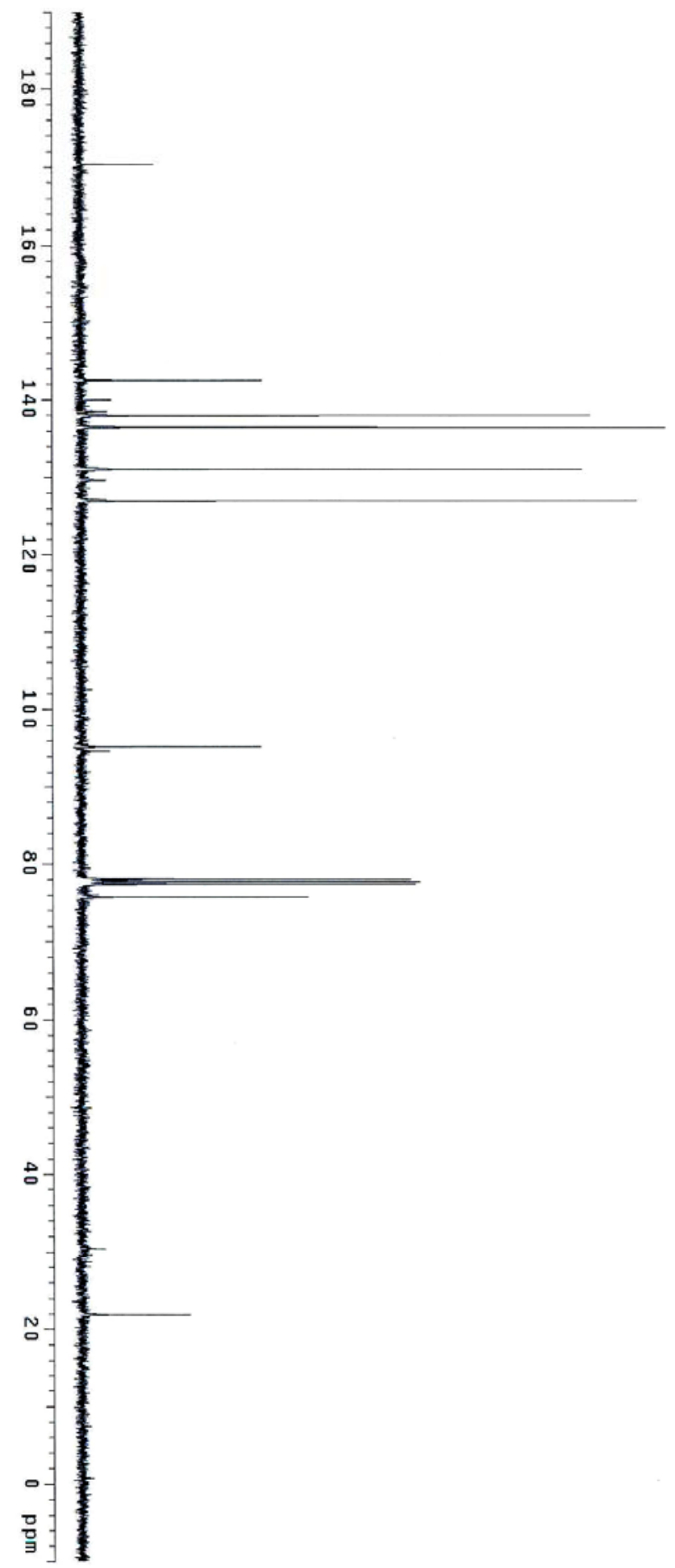



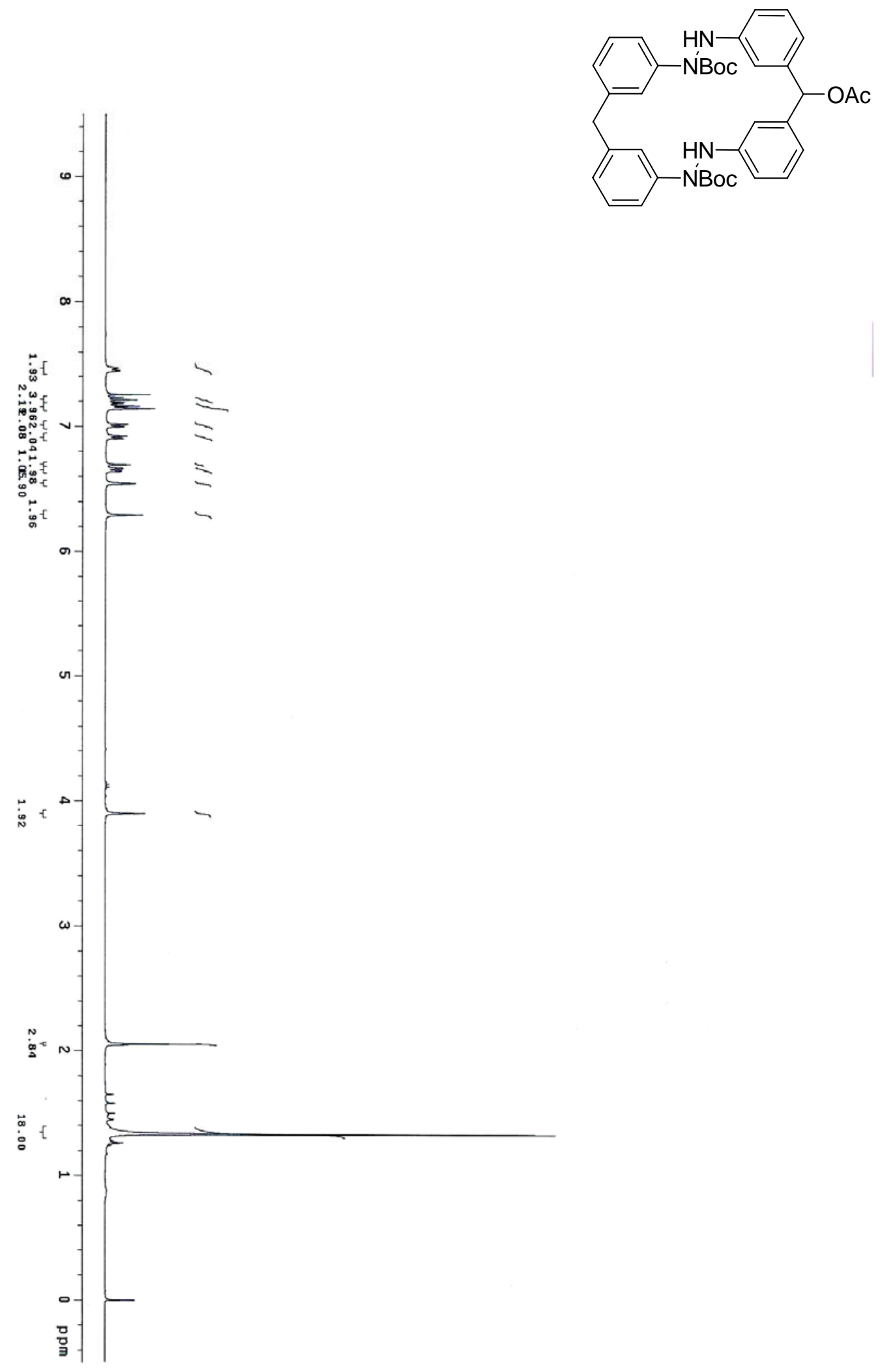


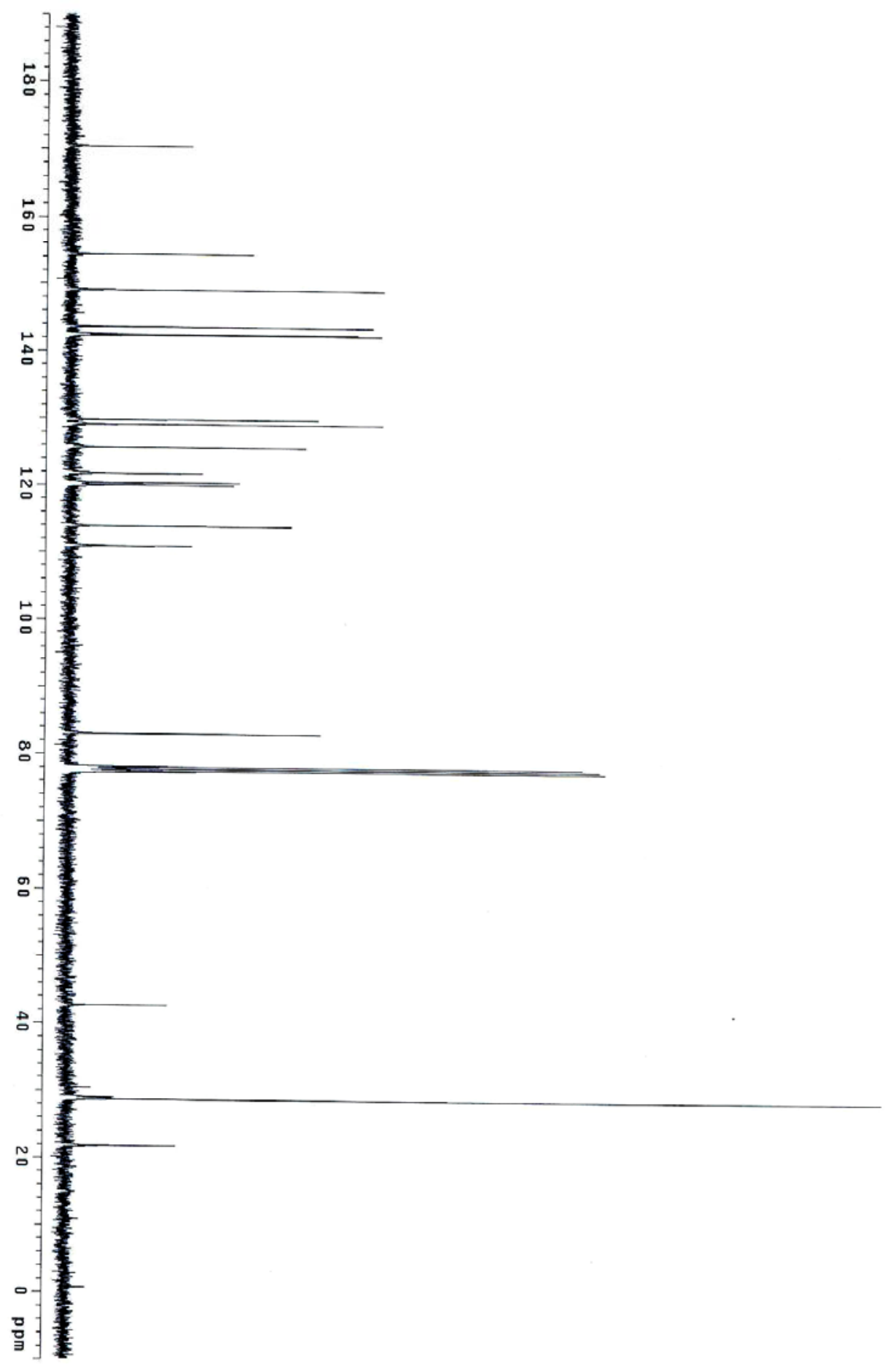



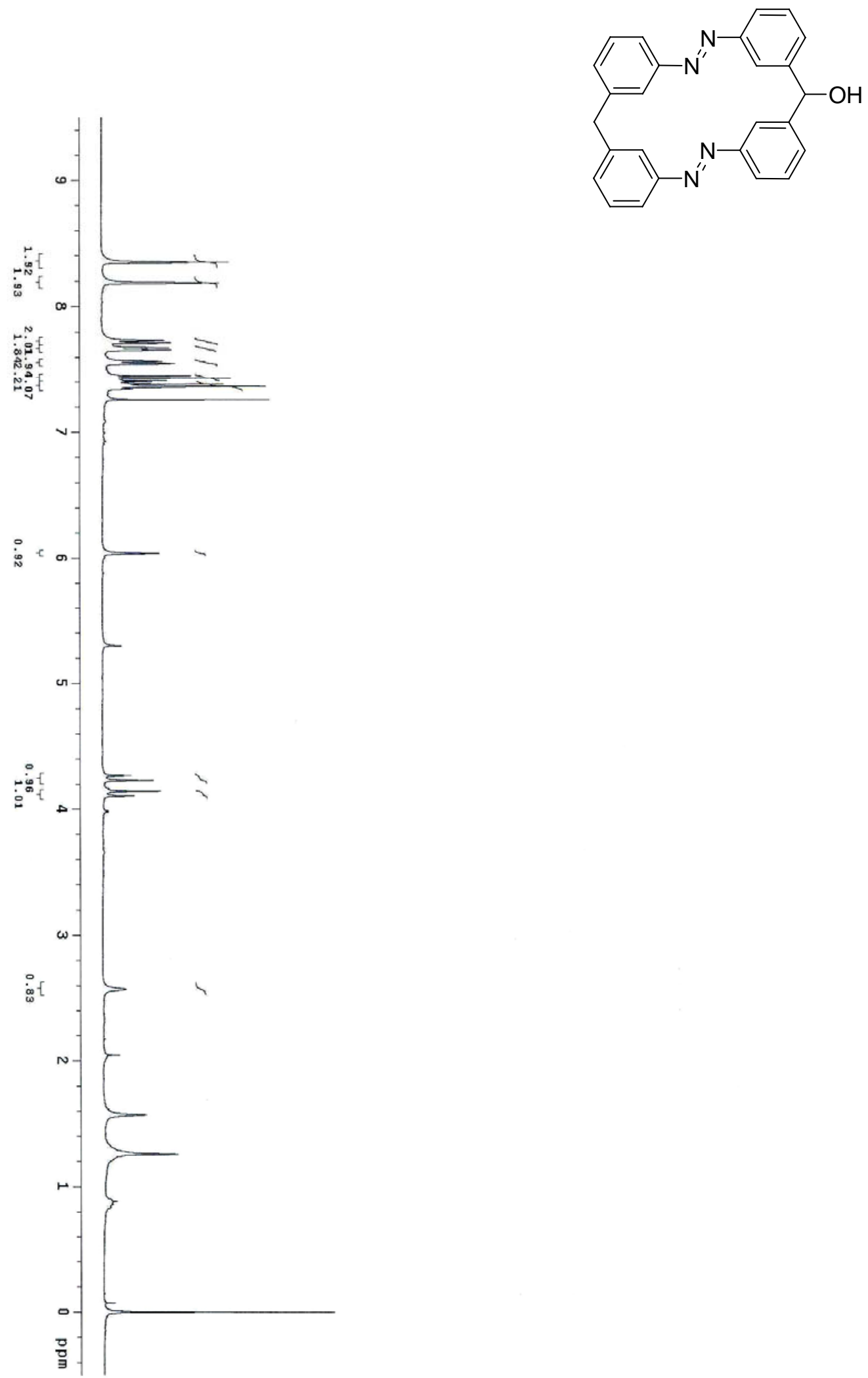


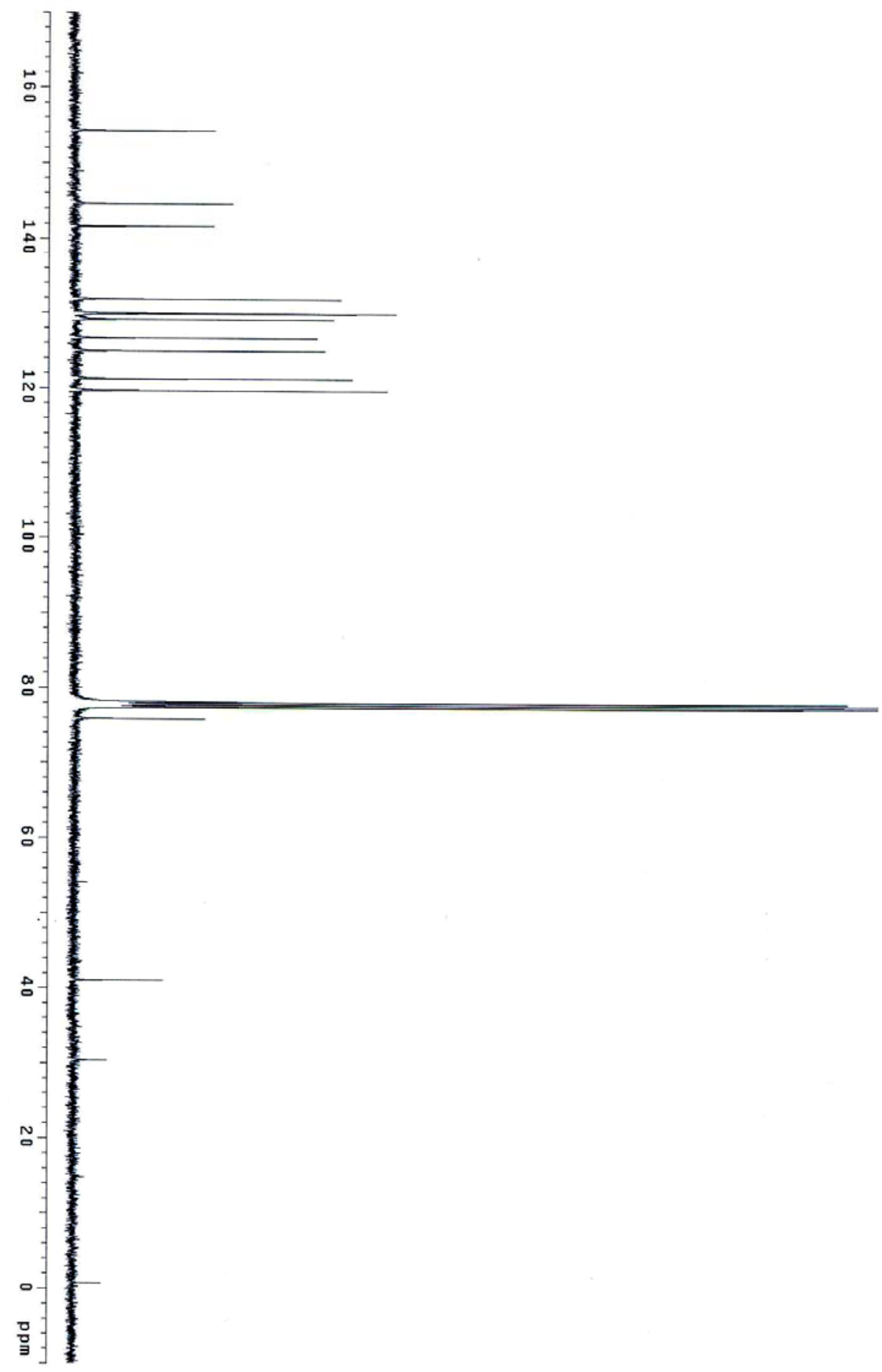

